\title{
Manuscript JO050306U
}

\section{revised \\ Regioselective N-functionalization of Tetraazacycloalkanes}

\author{
Frédéric Boschetti, ${ }^{a}$ Franck Denat, ${ }^{a}$ Enrique Espinosa, ${ }^{a}$ Alain Tabard, ${ }^{a}$ Yves Dory, ${ }^{b}$ \\ and Roger Guilard ${ }^{a *}$
}

\section{SUPPORTING INFORMATION}

${ }^{a}$ Université de Bourgogne, Laboratoire d’Ingénierie Moléculaire pour la Séparation et les Applications des Gaz, LIMSAG UMR 5633, Faculté des Sciences Gabriel, 6, boulevard Gabriel 21100 DIJON - France

${ }^{\mathrm{b}}$ Laboratoire de Synthèse Supramoléculaire, Departement de Chimie, Institut de Pharmacologie, Université de Sherbrooke, 3001, $12^{\mathrm{e}}$ avenue Nord, Sherbrooke (Québec), Canada J1H 5N4

Fax: +33 380396 120. E-mail: $\underline{\text { limsag@u-bourgogne.fr }}$ 


\section{Supporting Information Available}

1. TABLE S1. Crystal and Structure Refinement Data for 3, 9, 11, 19, 27 and 30 (2 pages: S1-S2).

2. Computer modeling energies for the various studied structures (5 pages: S3-S7).

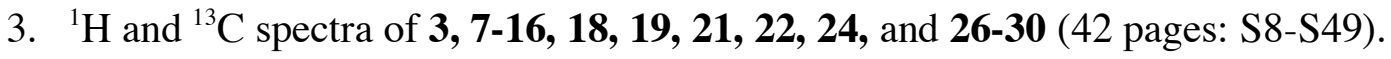

4. Crystallographic data (CIF files) corresponding to the structural analysis of 9, 11, 27 and 30. The structures have been deposited to the Cambridge Crystallographic Data Centre, CCDC Nos. $216209-216212$.

5. Final data-validation reports for CIFS. 


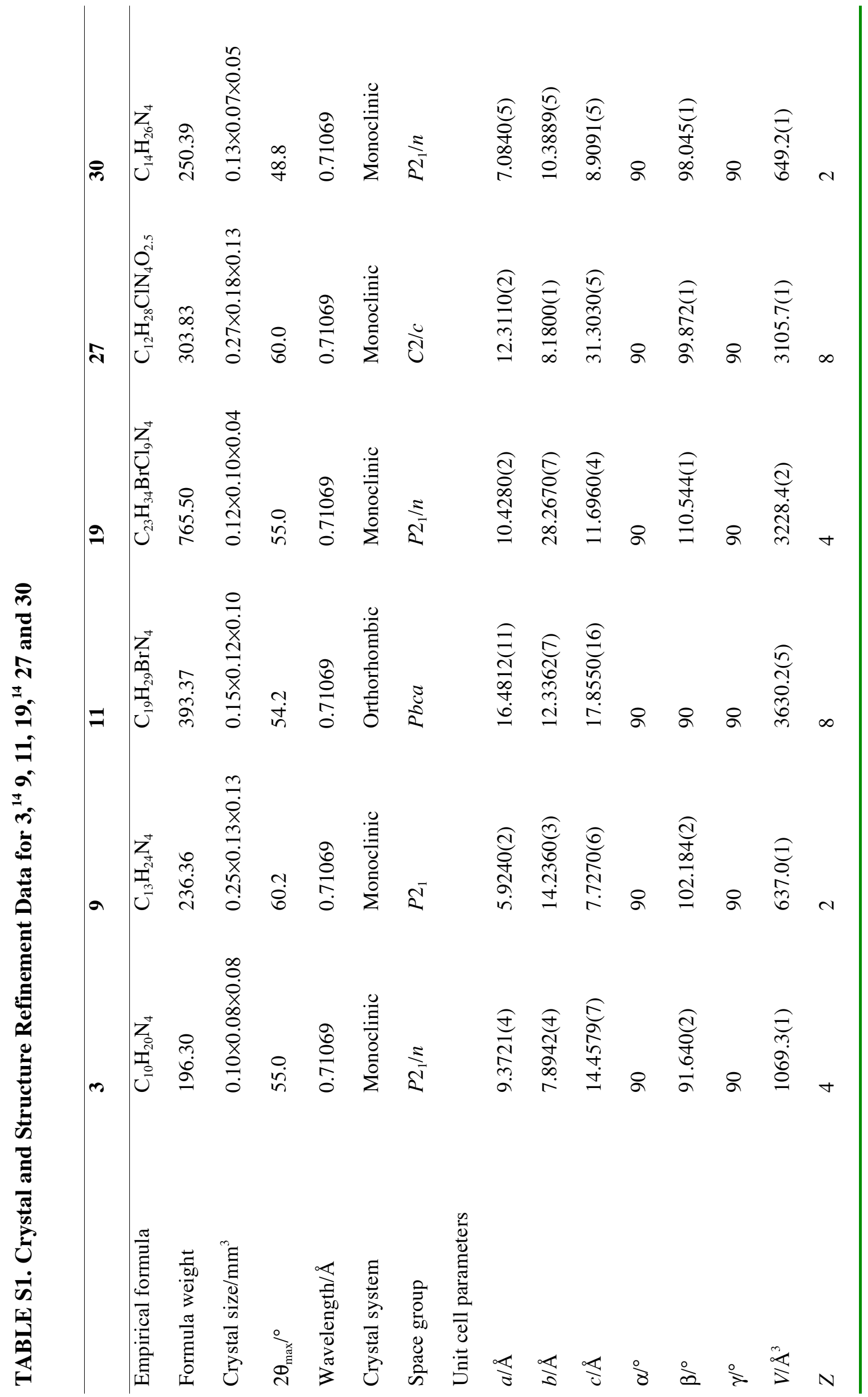




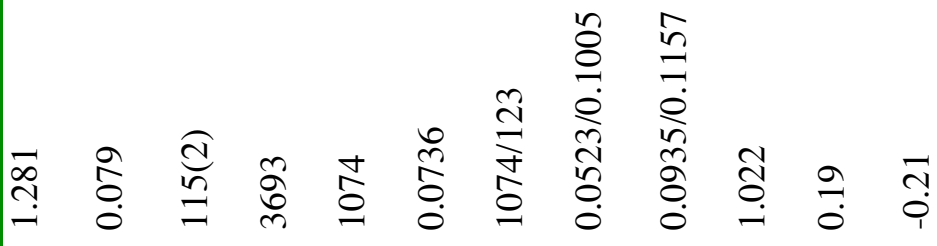

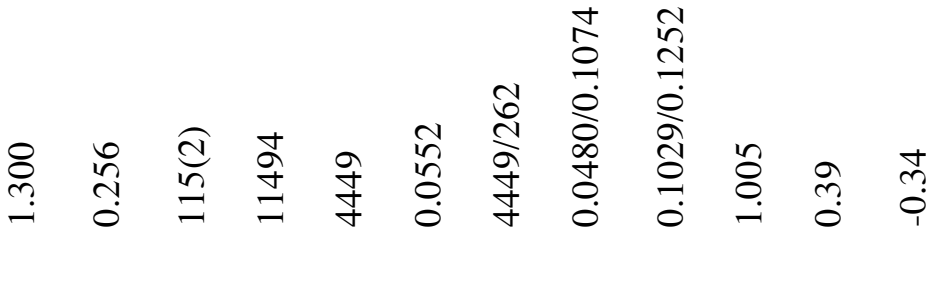

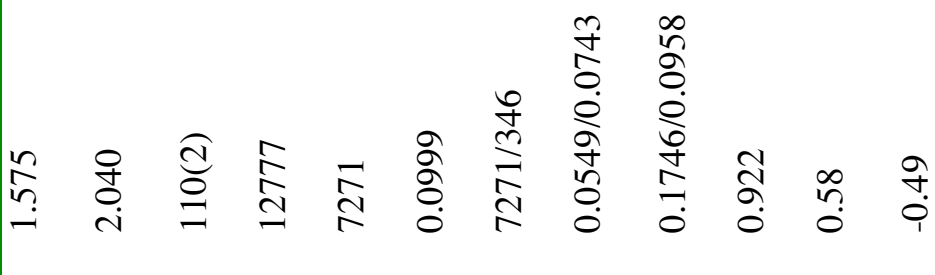

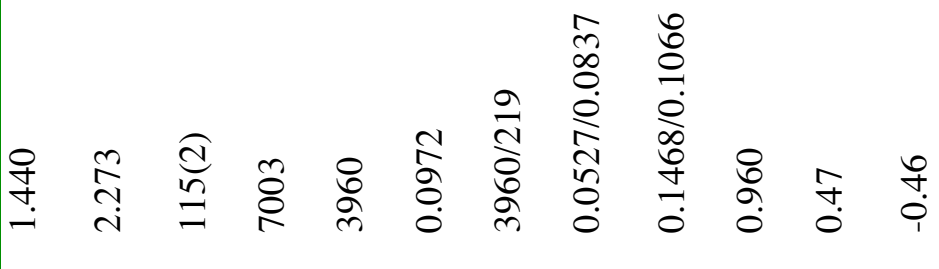

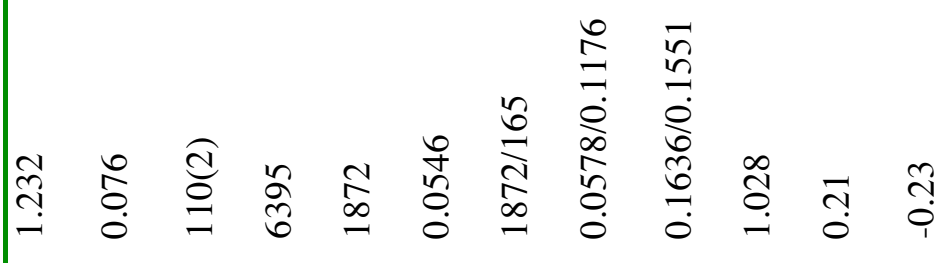

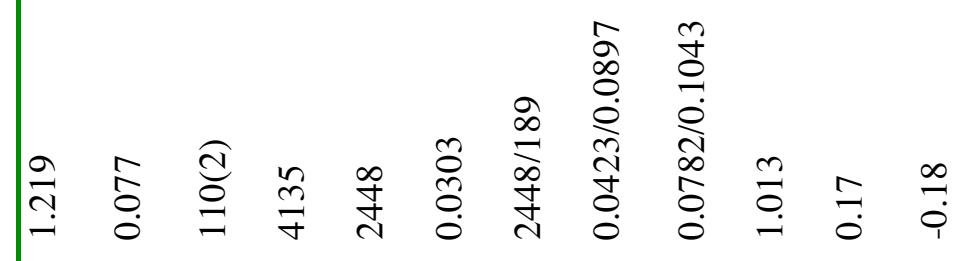




\section{Molecular modeling energies for the various studied structures}

\begin{tabular}{|c|c|c|c|}
\hline \multicolumn{2}{|l|}{ Compound } & I (kcal/mol) & DFT (Hartree) \\
\hline & 3 & 28.62 & \\
\hline & 3 & 29.17 & \\
\hline & 3 & 27.23 & -611.6851388 \\
\hline & 3 & 25.00 & -611.6905449 \\
\hline & 4 & 31.27 & \\
\hline & 4 & 31.61 & \\
\hline & 4 & 27.75 & -611.6762976 \\
\hline & 4 & 25.44 & -611.6834703 \\
\hline & & 35.04 & -611.6832287 \\
\hline & & 33.49 & -611.6898696 \\
\hline & & 36.76 & \\
\hline & & 39.15 & \\
\hline & & 34.00 & -611.6833392 \\
\hline & & 33.24 & -611.6764341 \\
\hline
\end{tabular}




\begin{tabular}{|c|c|c|}
\hline Compound & I (kcal/mol) & DFT (Hartree) \\
\hline & 30.91 & -650.9582383 \\
\hline & 28.68 & -650.9647208 \\
\hline & 33.42 & \\
\hline & 33.07 & \\
\hline & 40.21 & \\
\hline & 36.73 & -650.9602846 \\
\hline & 37.84 & -650.9529996 \\
\hline & 23.38 & -569.0597460 \\
\hline & 29.00 & \\
\hline & 25.99 & \\
\hline & 29.68 & \\
\hline & 37.33 & \\
\hline & 32.42 & \\
\hline & 32.09 & -569.0551443 \\
\hline
\end{tabular}




I (kcal/mol)




(kcal/mol)




\begin{tabular}{|c|c|c|c|}
\hline Compound & & $\mathrm{I}(\mathrm{kcal} / \mathrm{mol})$ & DFT (Hartree) \\
\hline & & 21.68 & -611.6870342 \\
\hline & & 15.57 & -611.6930939 \\
\hline & & 19.76 & -611.6904926 \\
\hline & & 21.16 & -611.6940121 \\
\hline & & 42.78 & -767.6046873 \\
\hline & & 35.65 & \\
\hline & 9 & 45.71 & -728.3353079 \\
\hline & 30 & 49.02 & -767.6074527 \\
\hline
\end{tabular}



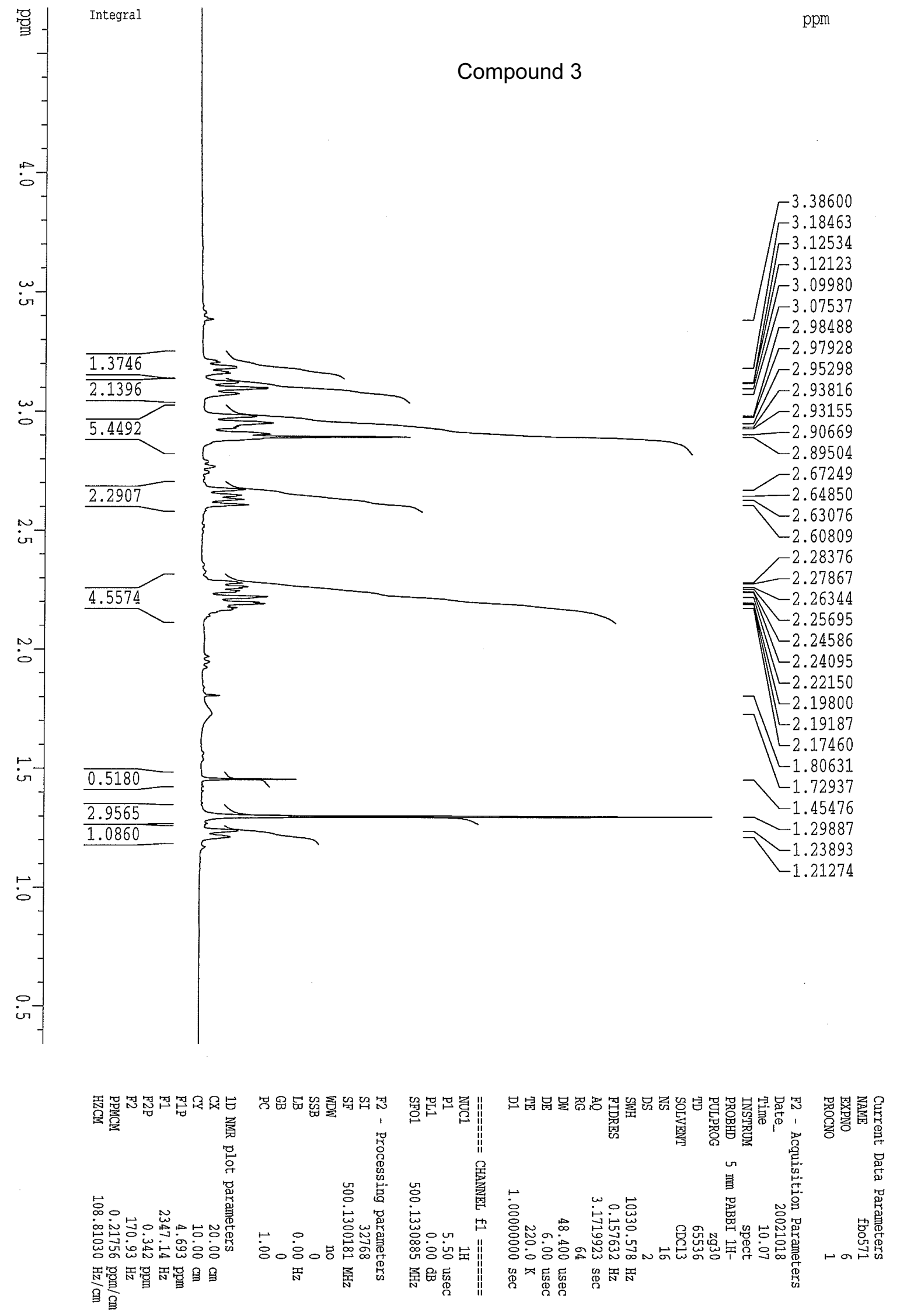


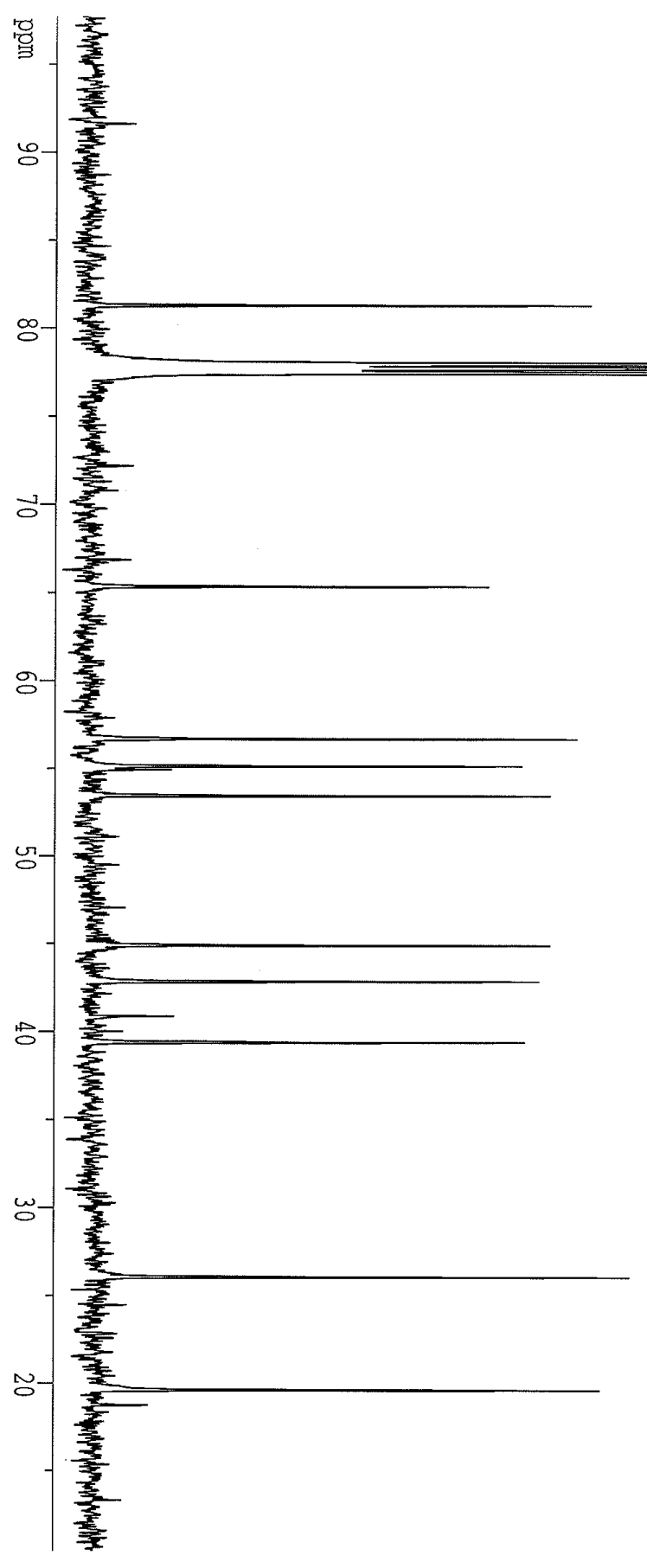

\section{Compound 3}

$$
\text { . }
$$



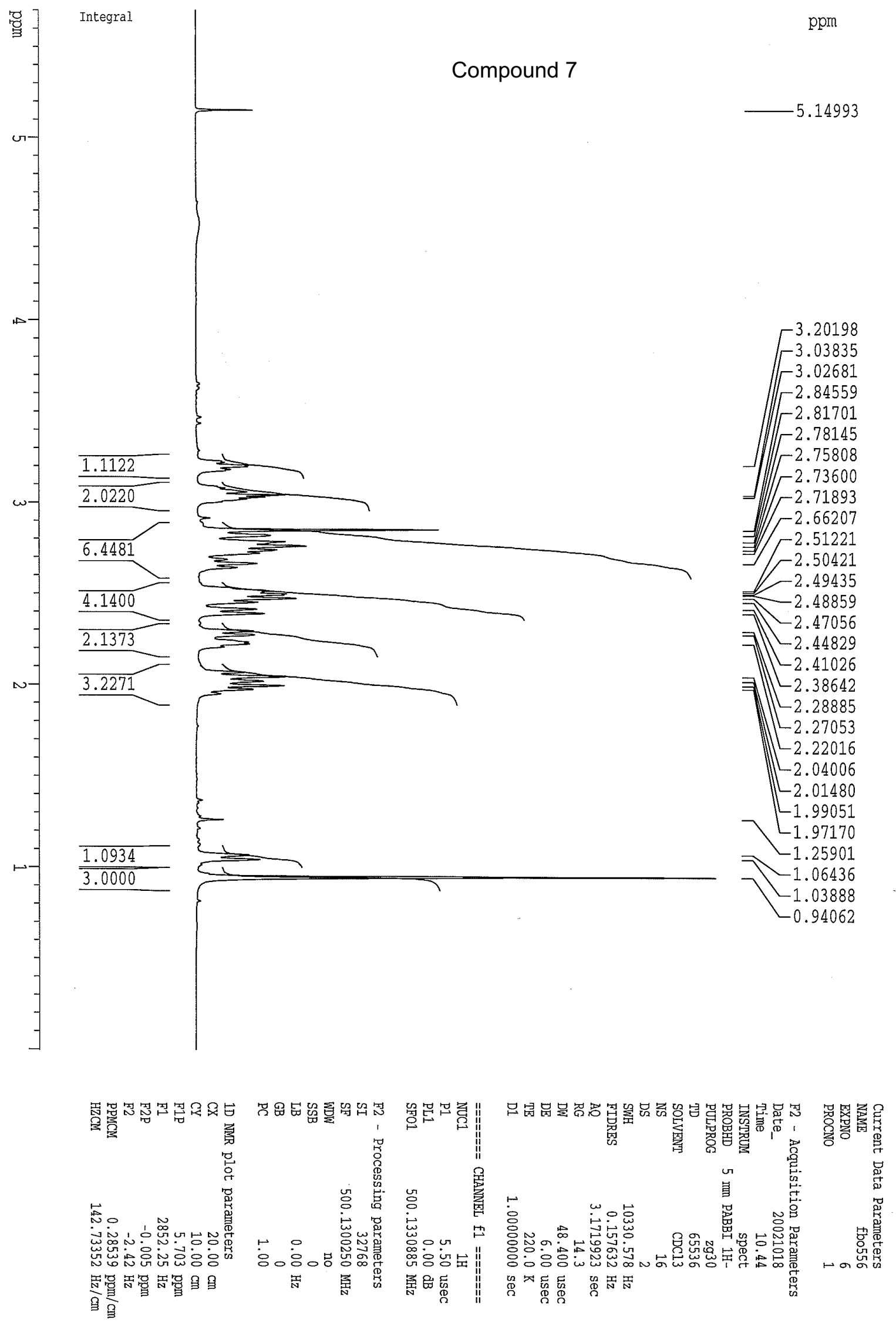

Regioselective N-functionalization of Tetraazacycloalkanes 


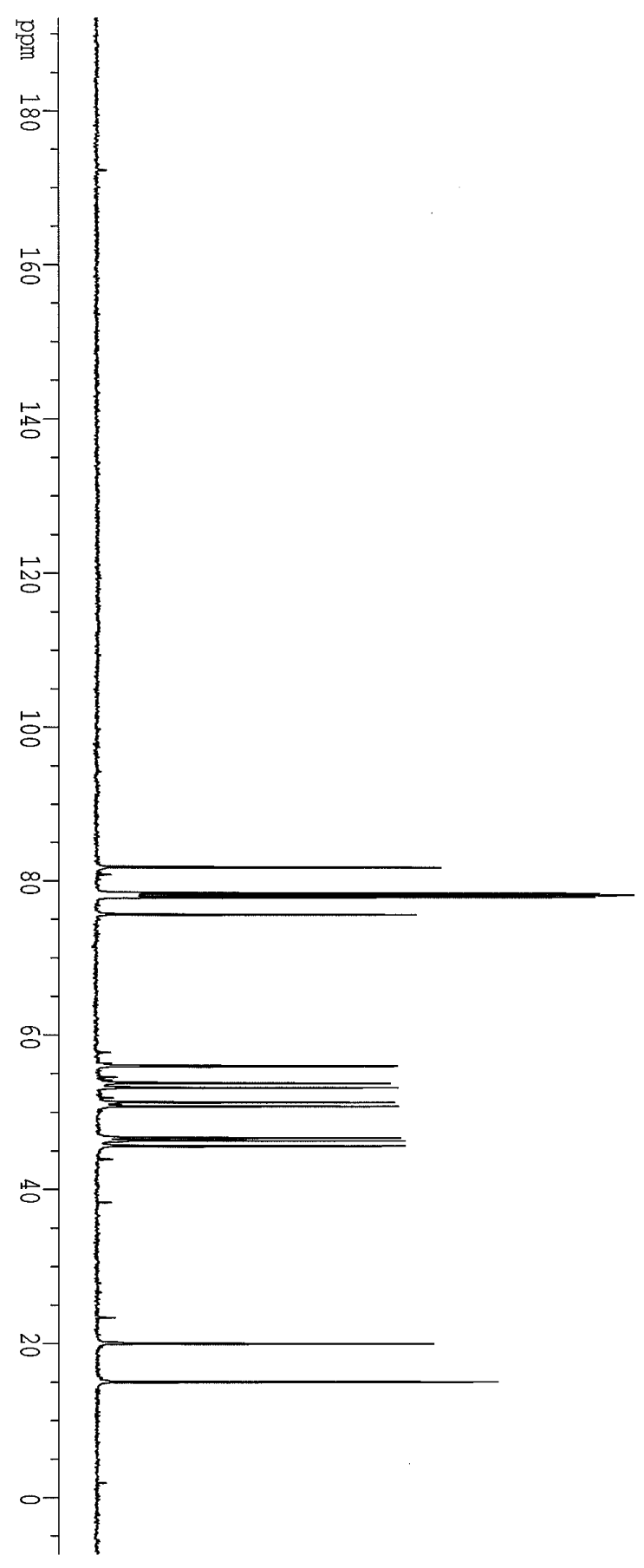

\section{Compound 7}

ppm
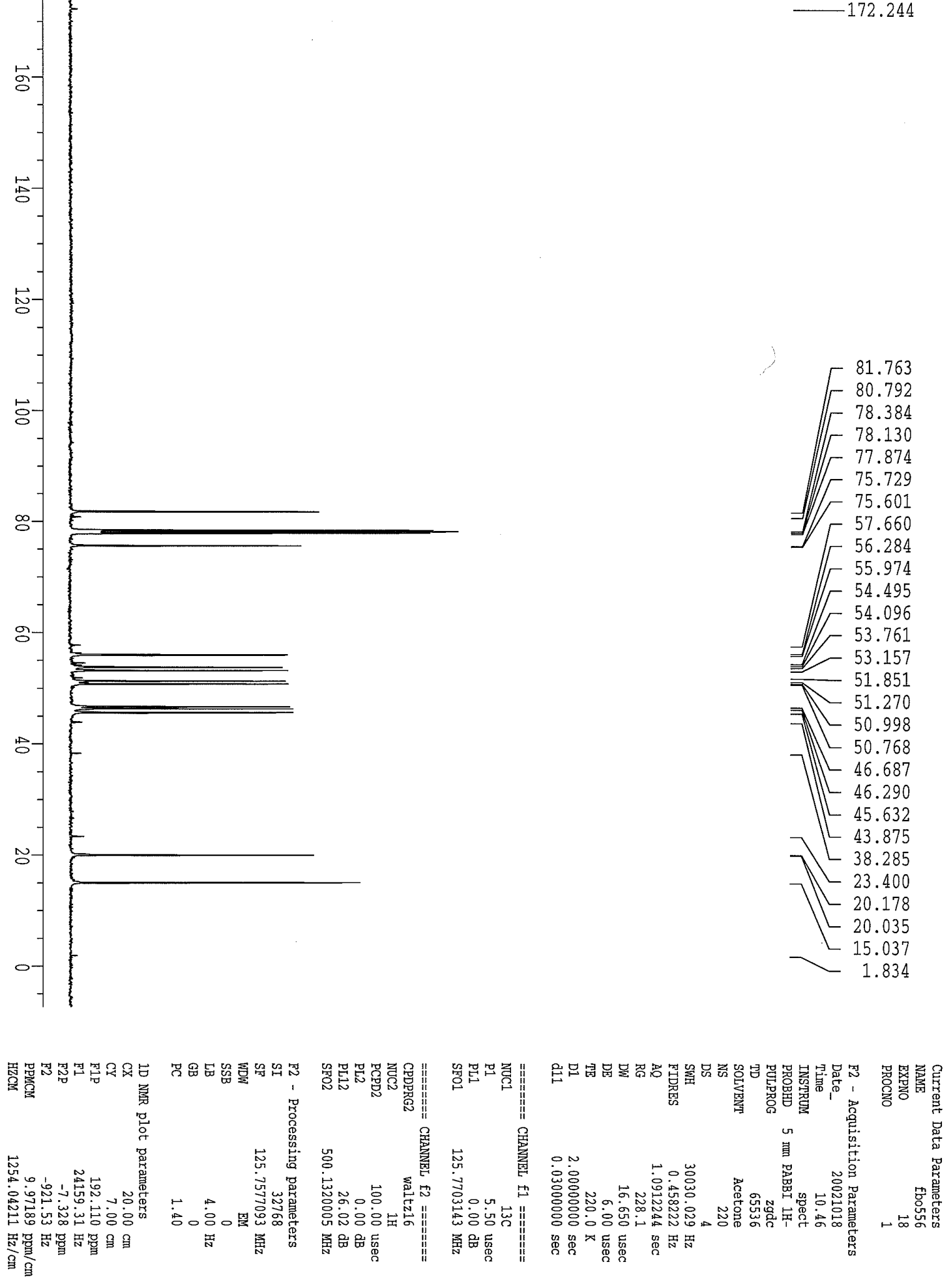

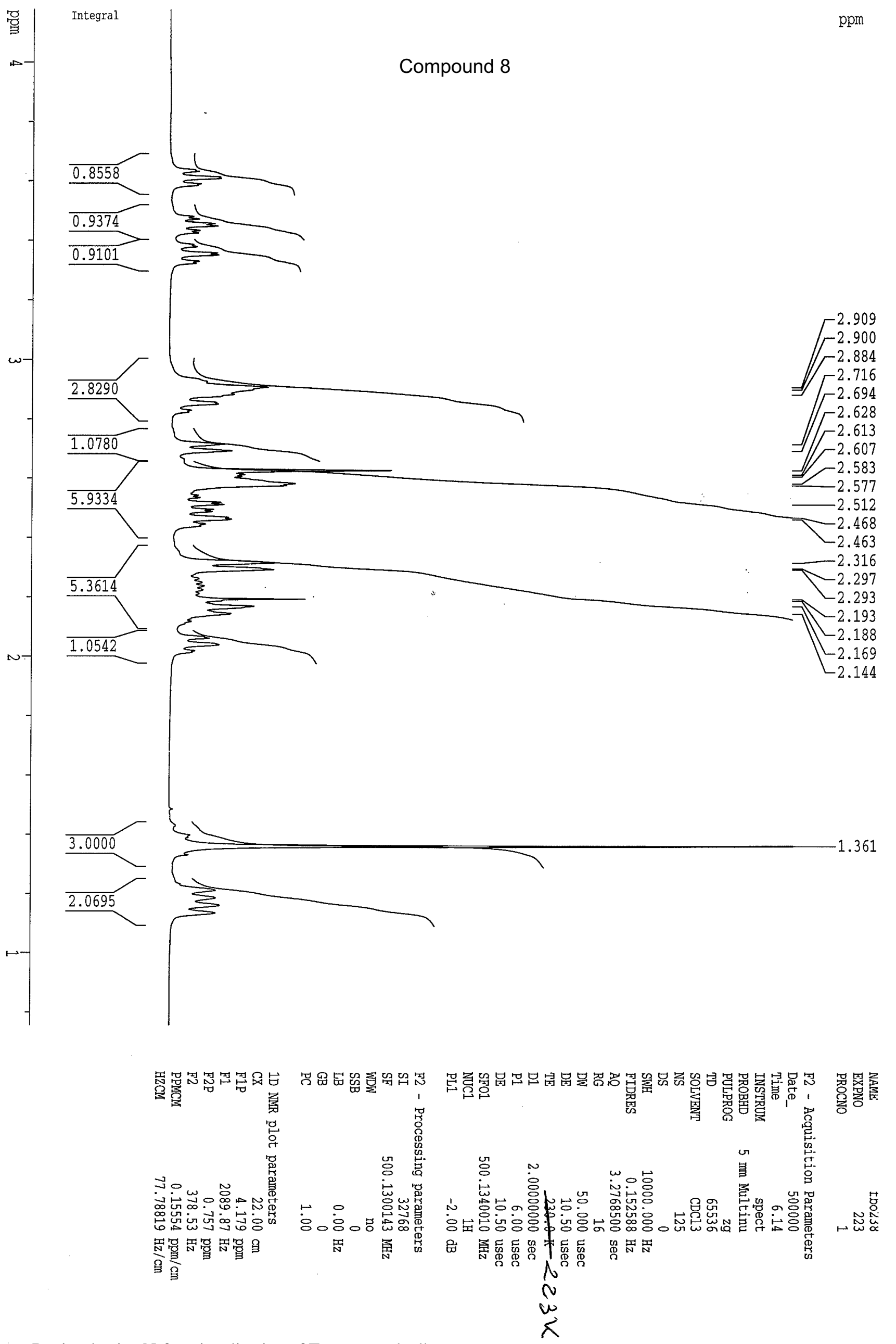

Regioselective N-functionalization of Tetraazacycloalkanes 

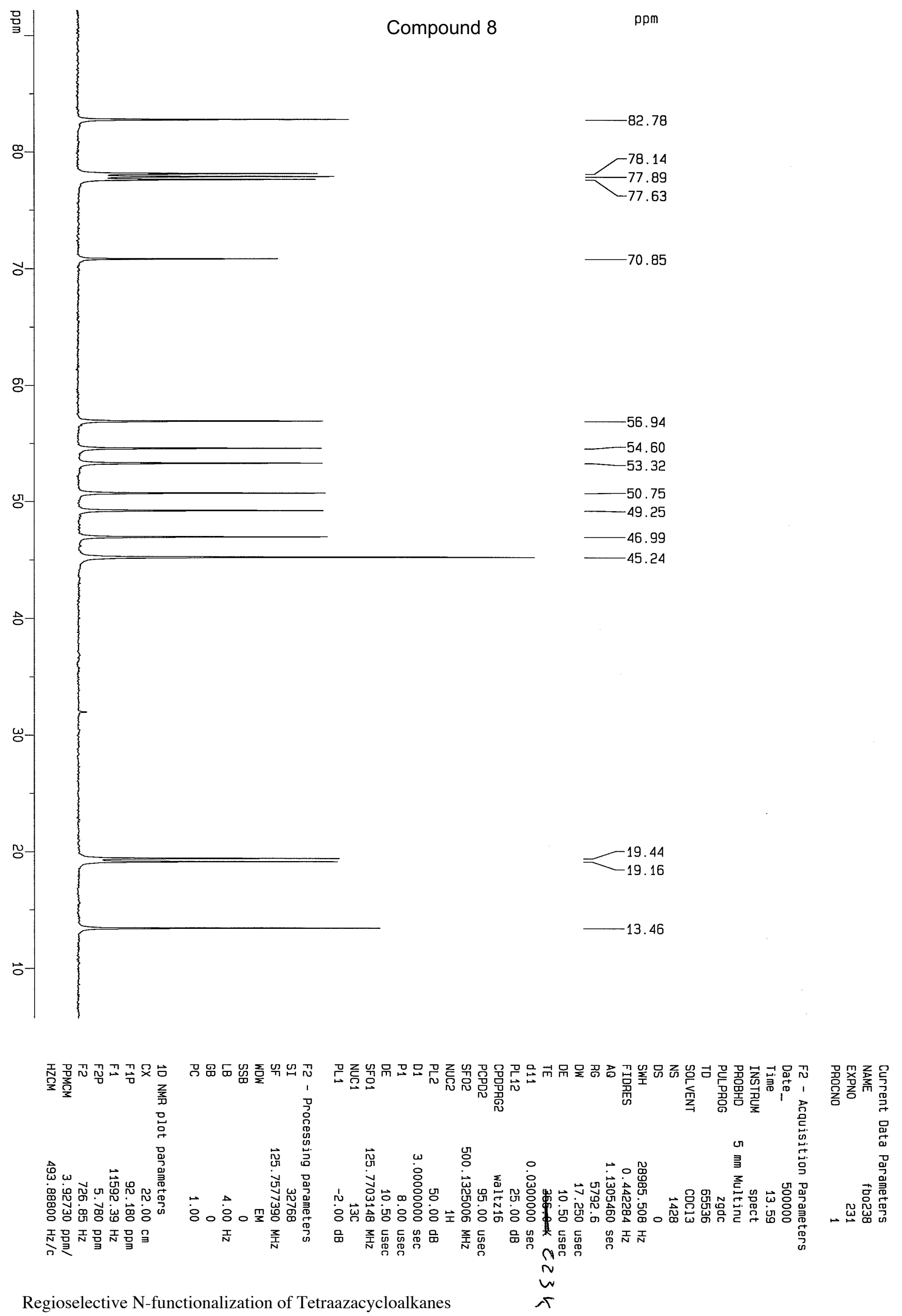

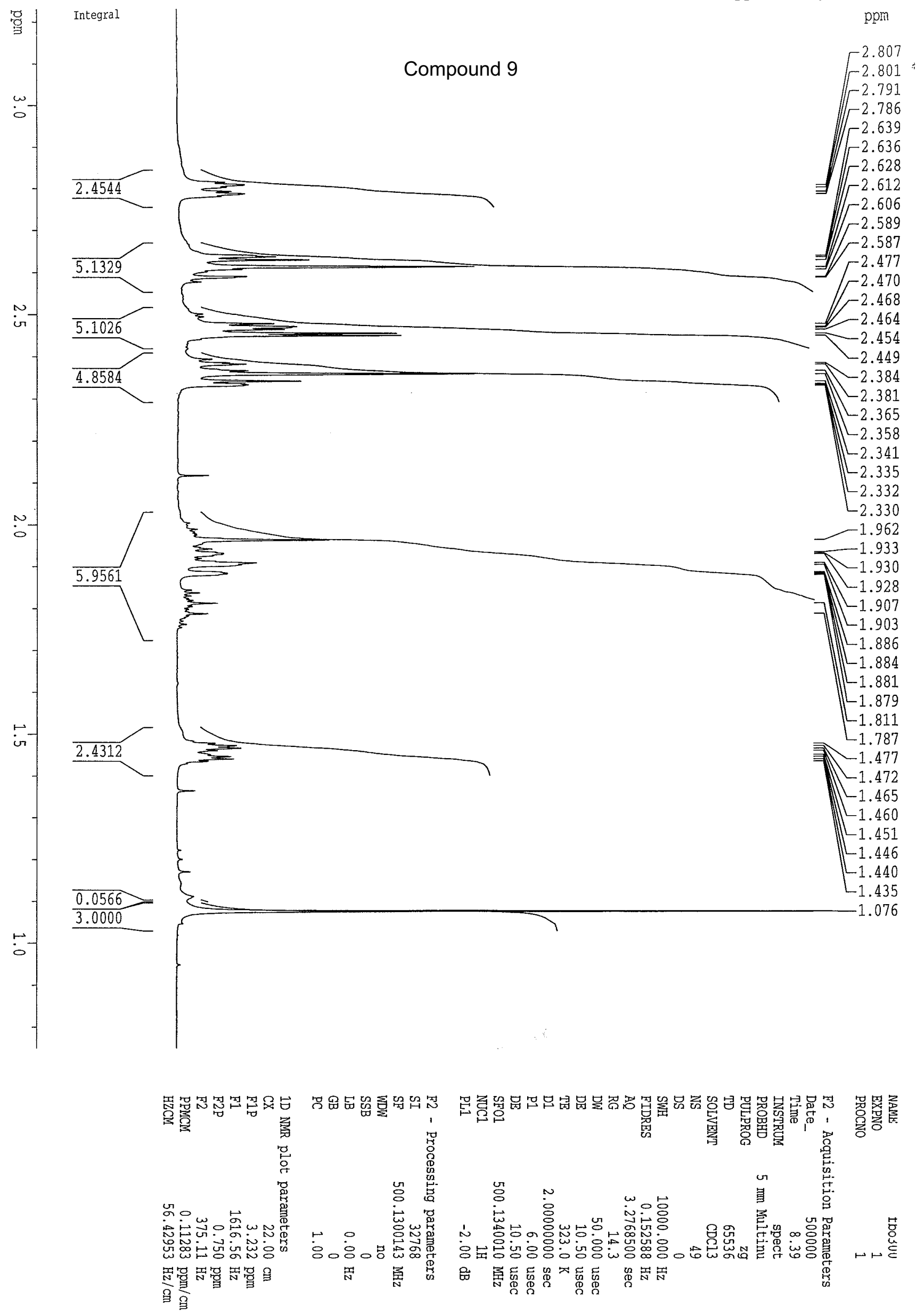


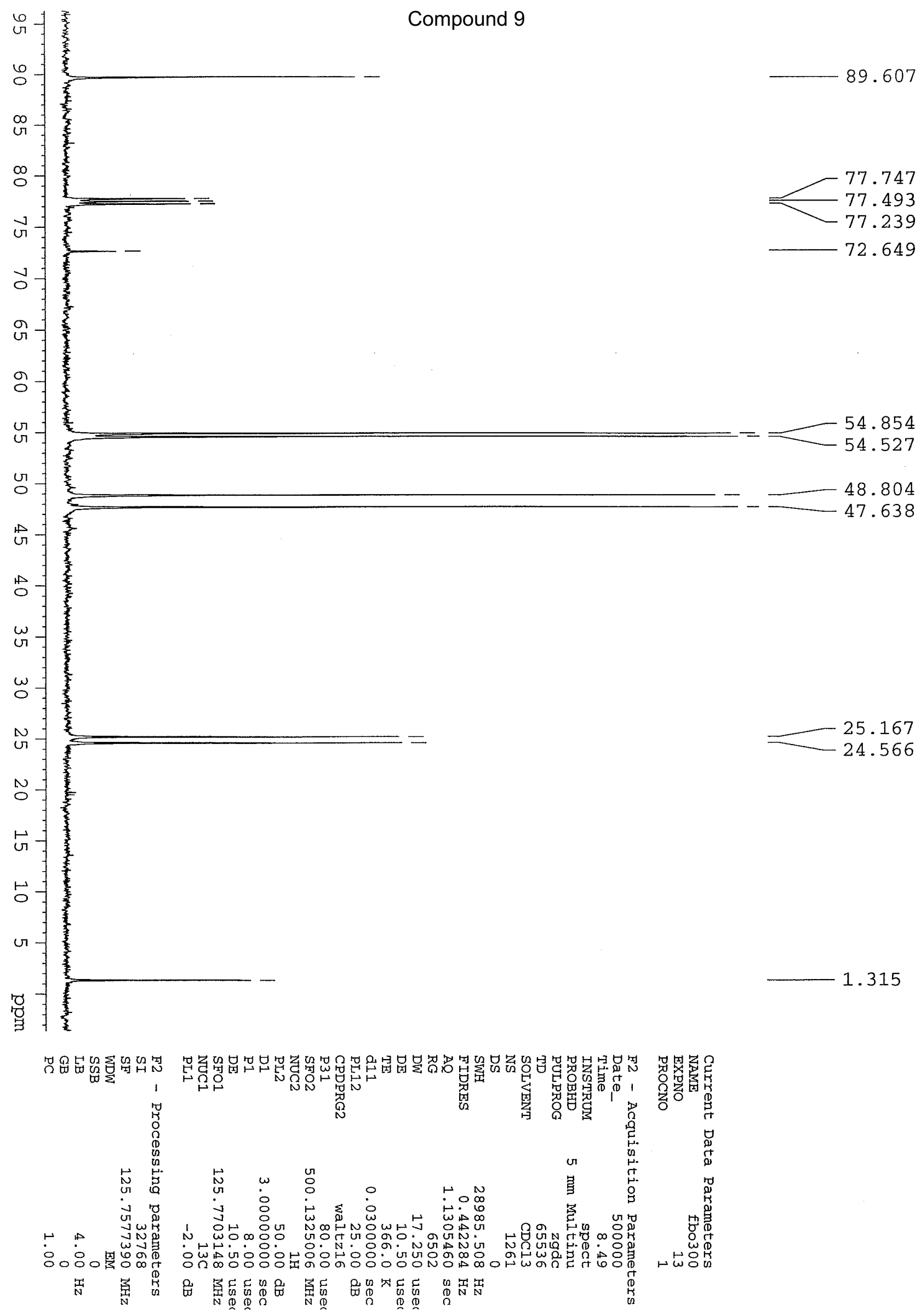

Regioselective N-functionalization of Tetraazacycloalkanes 

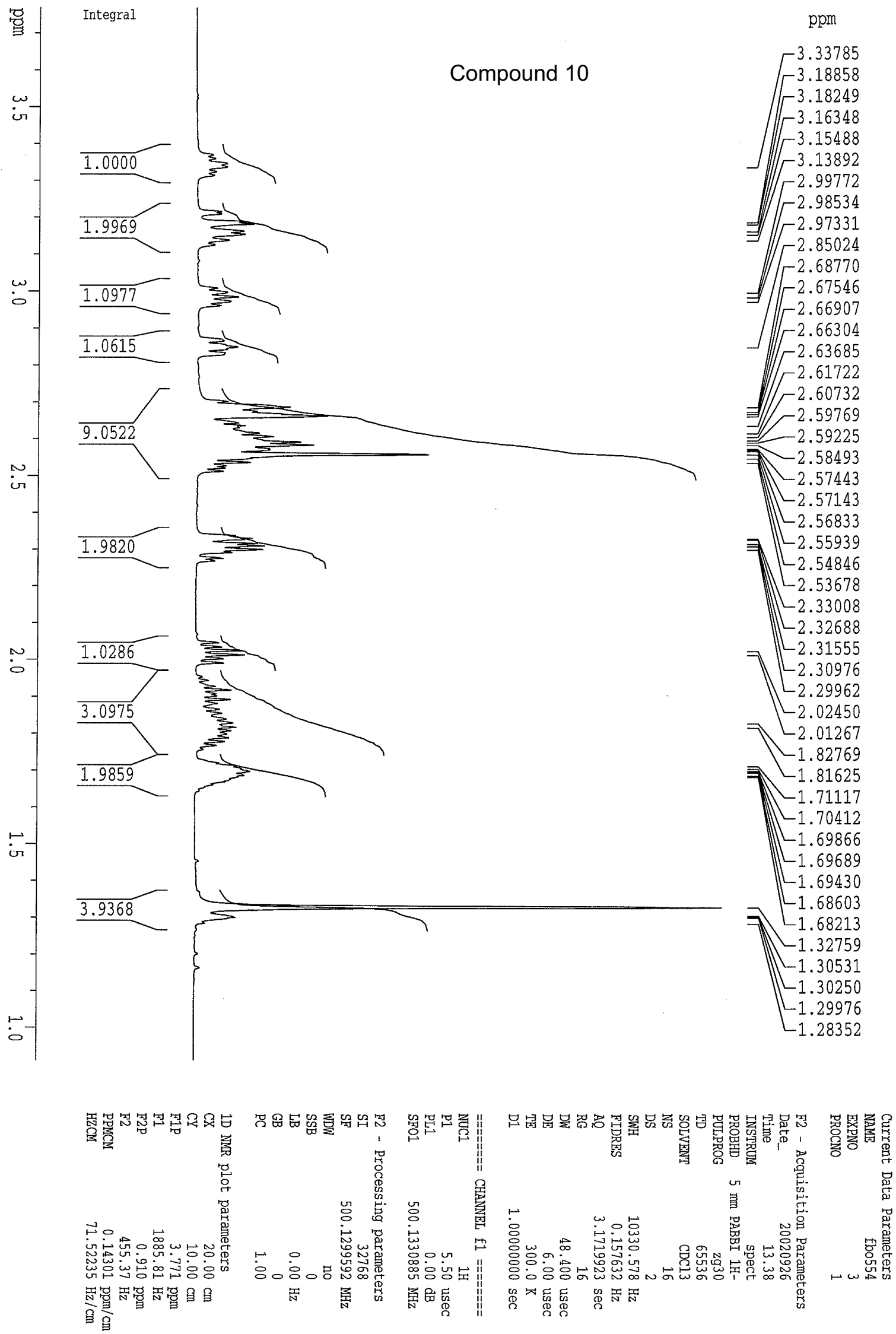


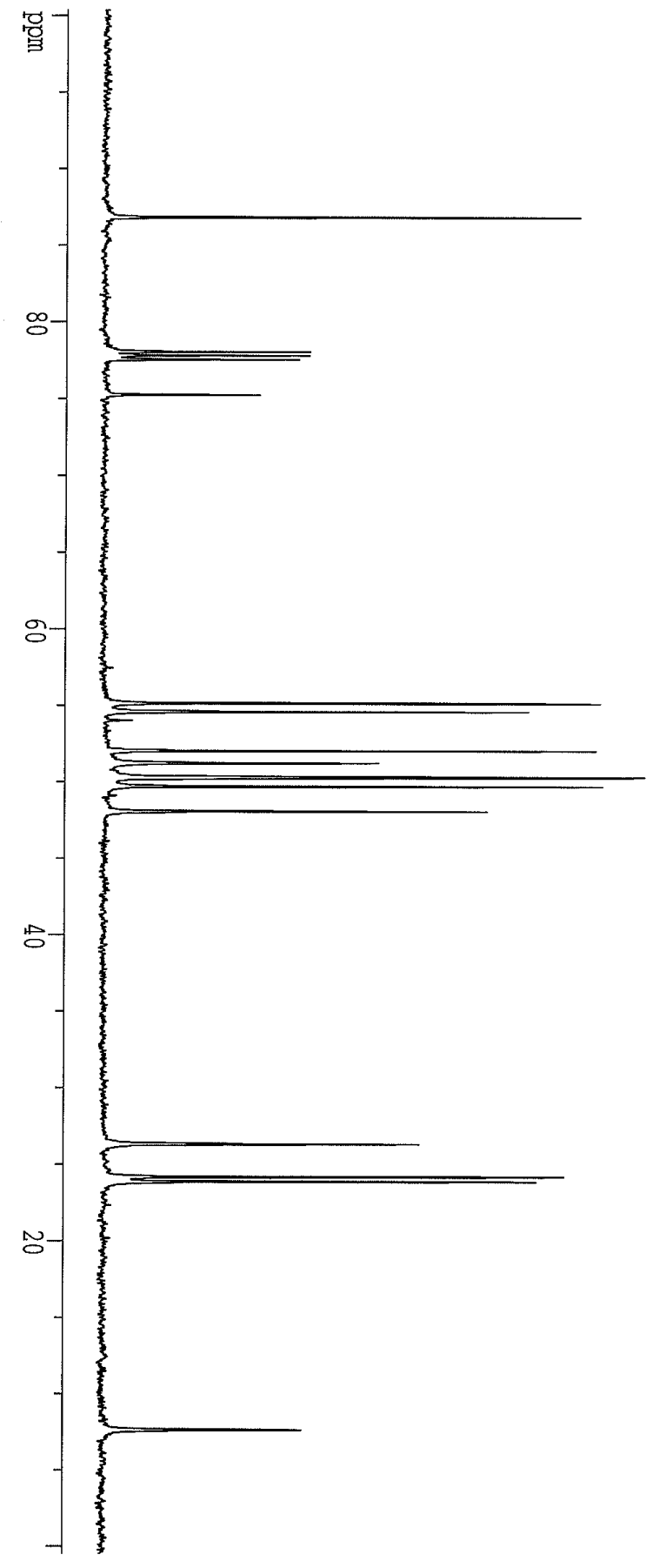

\section{Compound 10}
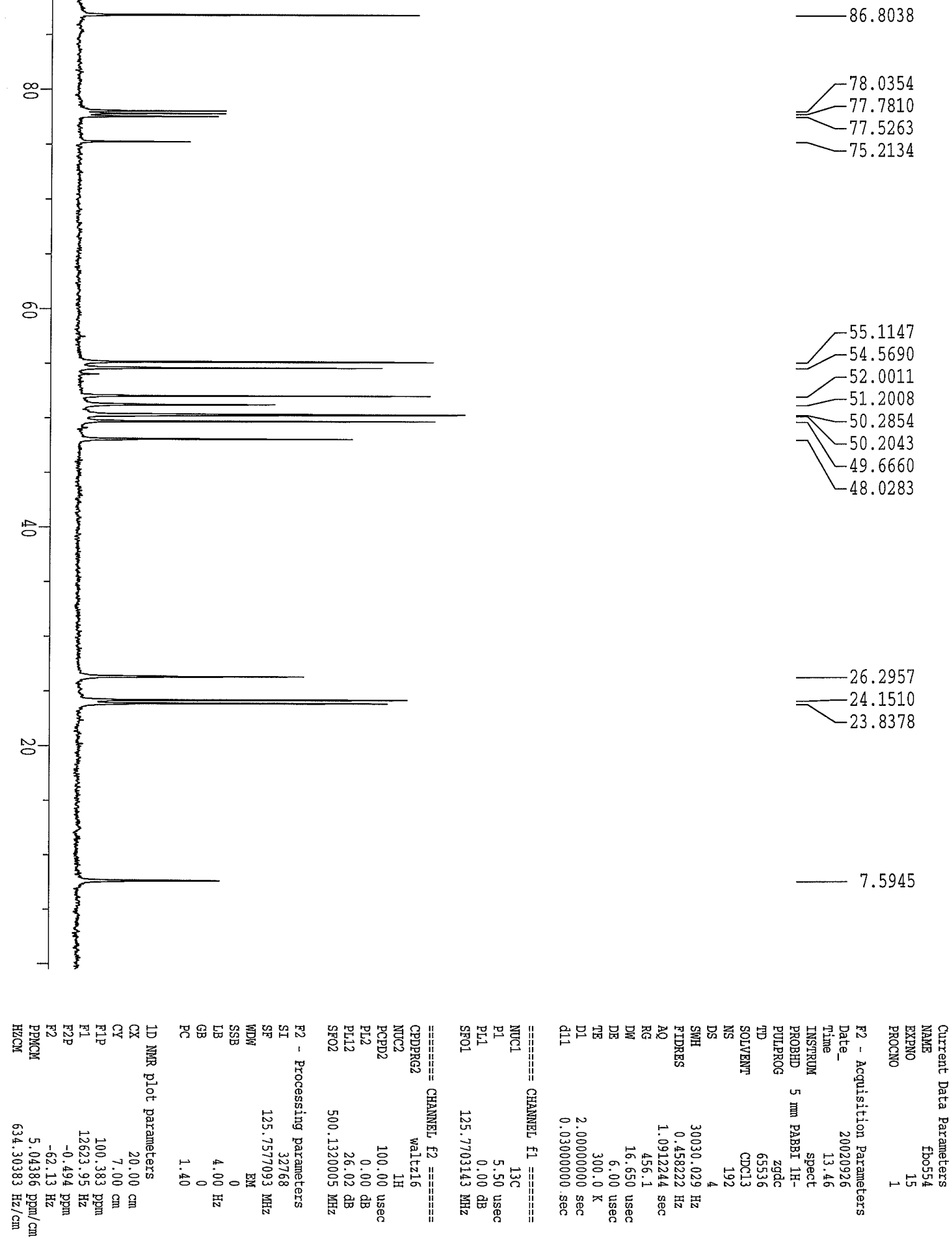

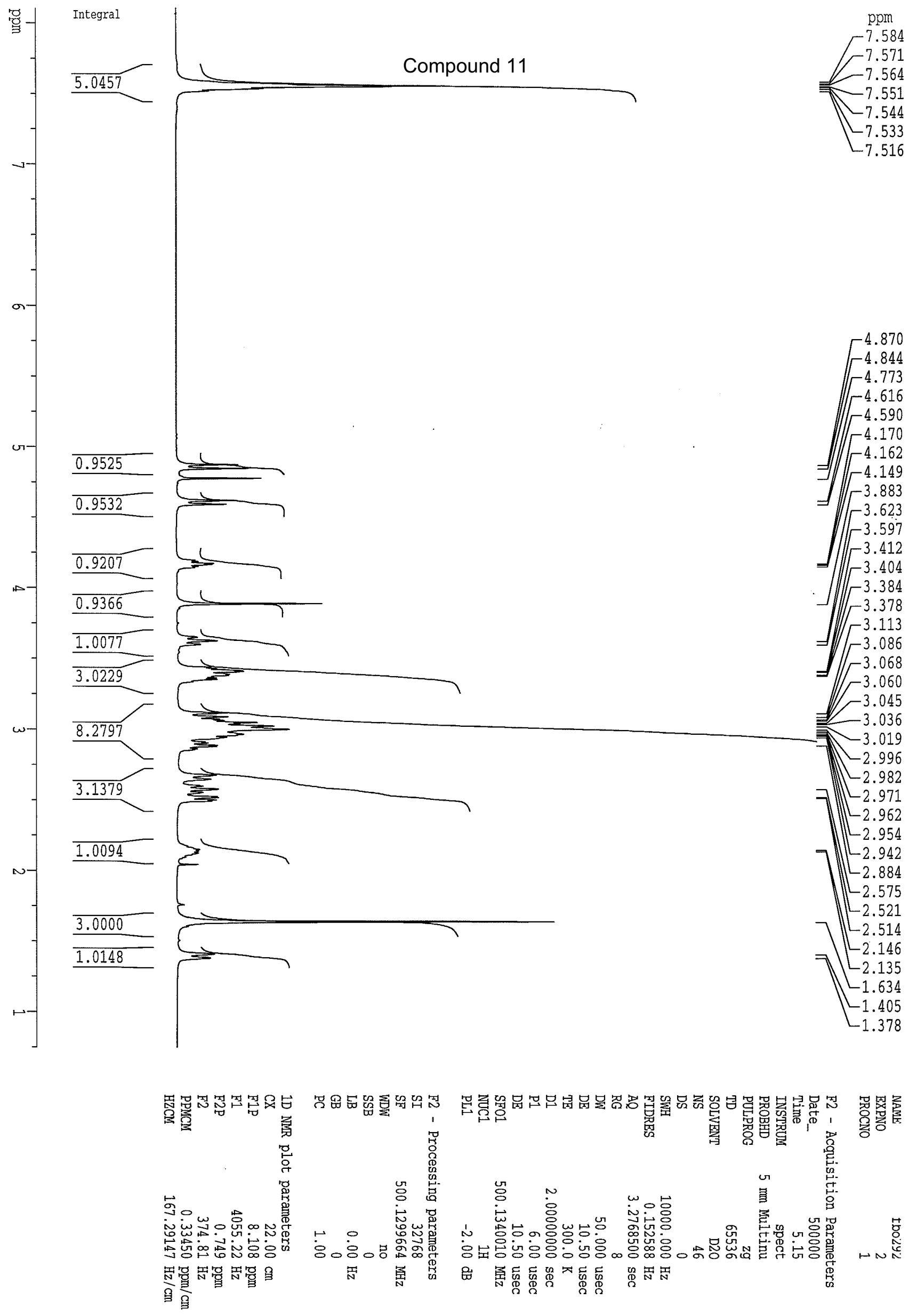

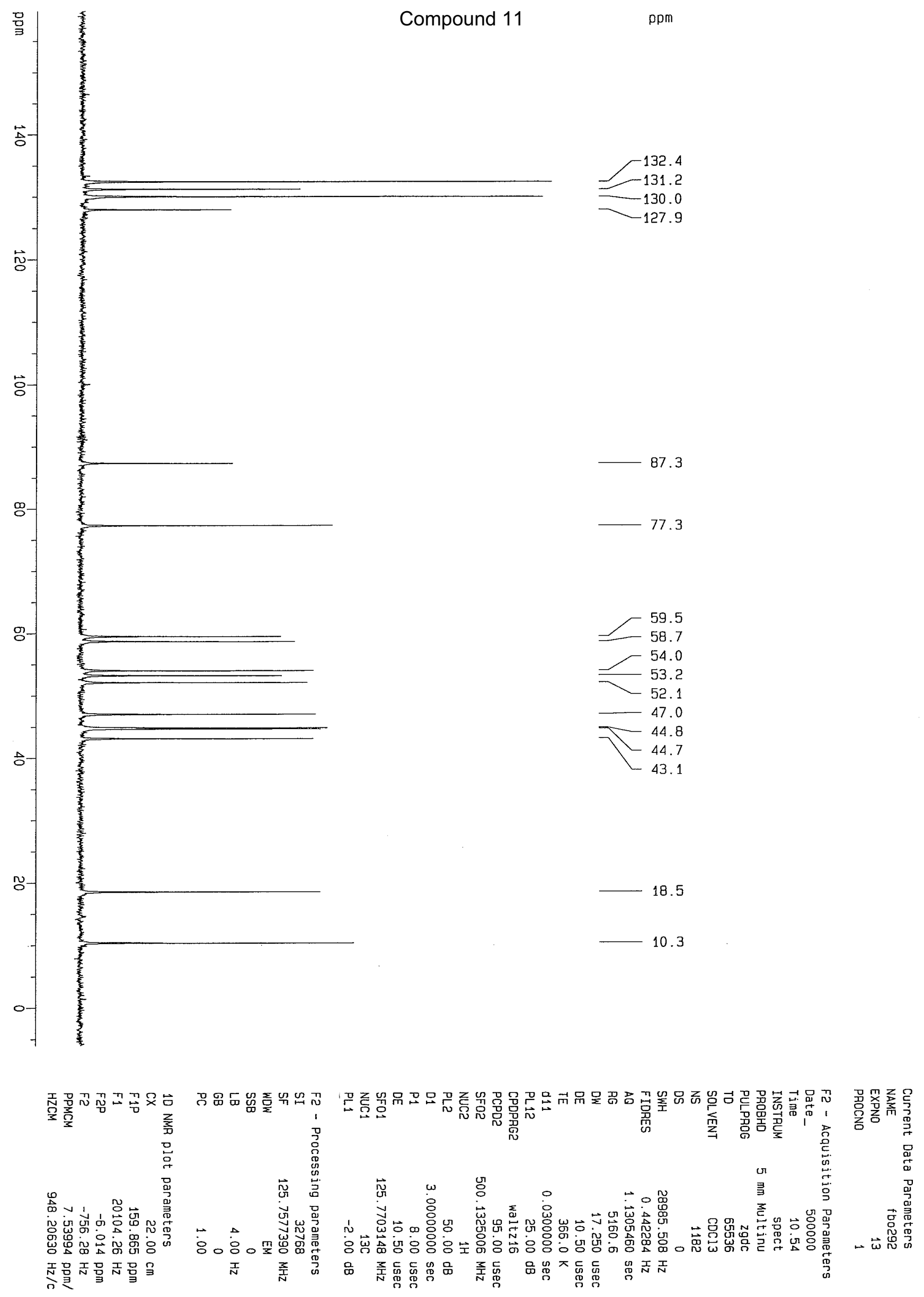

Regioselective N-functionalization of Tetraazacycloalkanes 

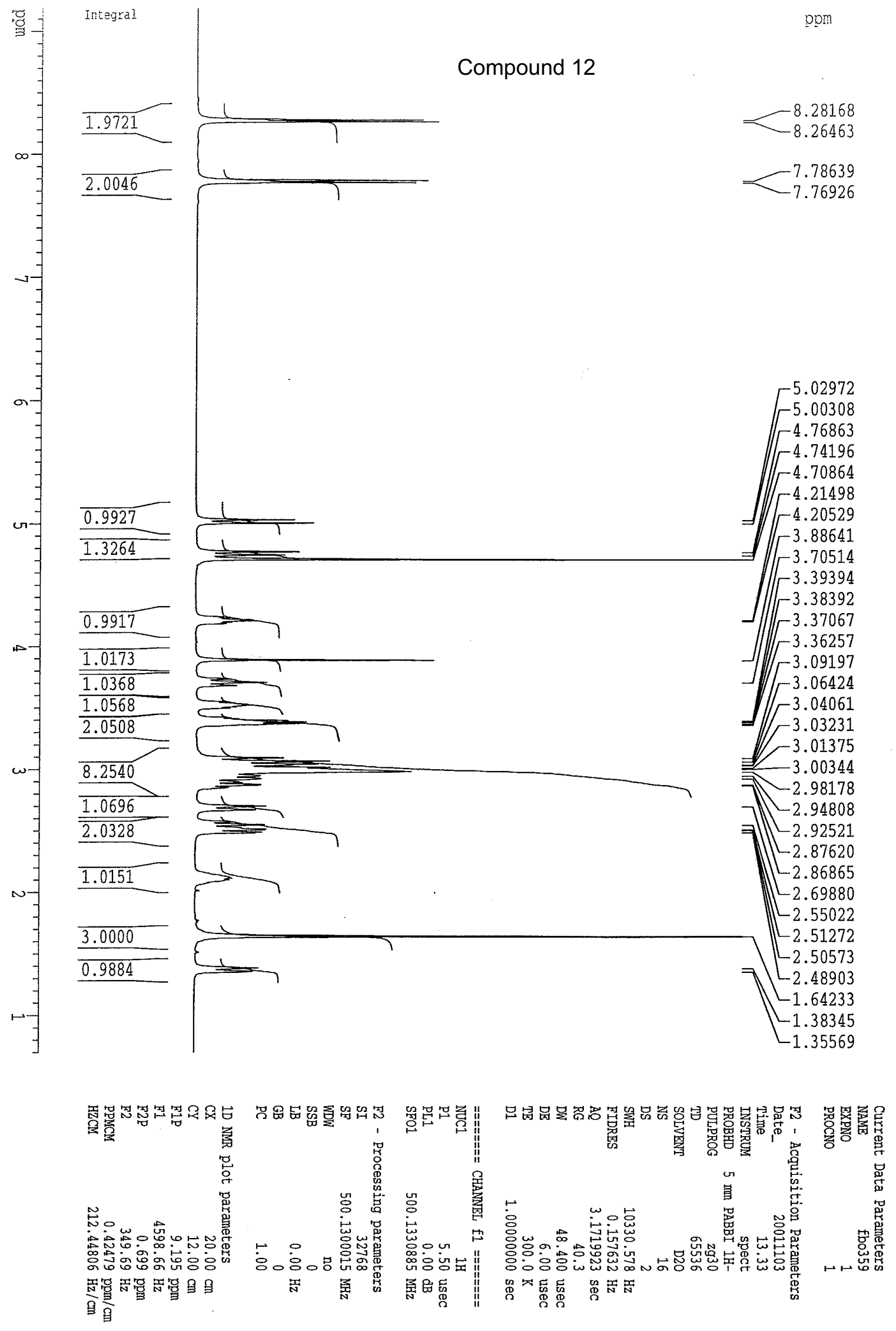


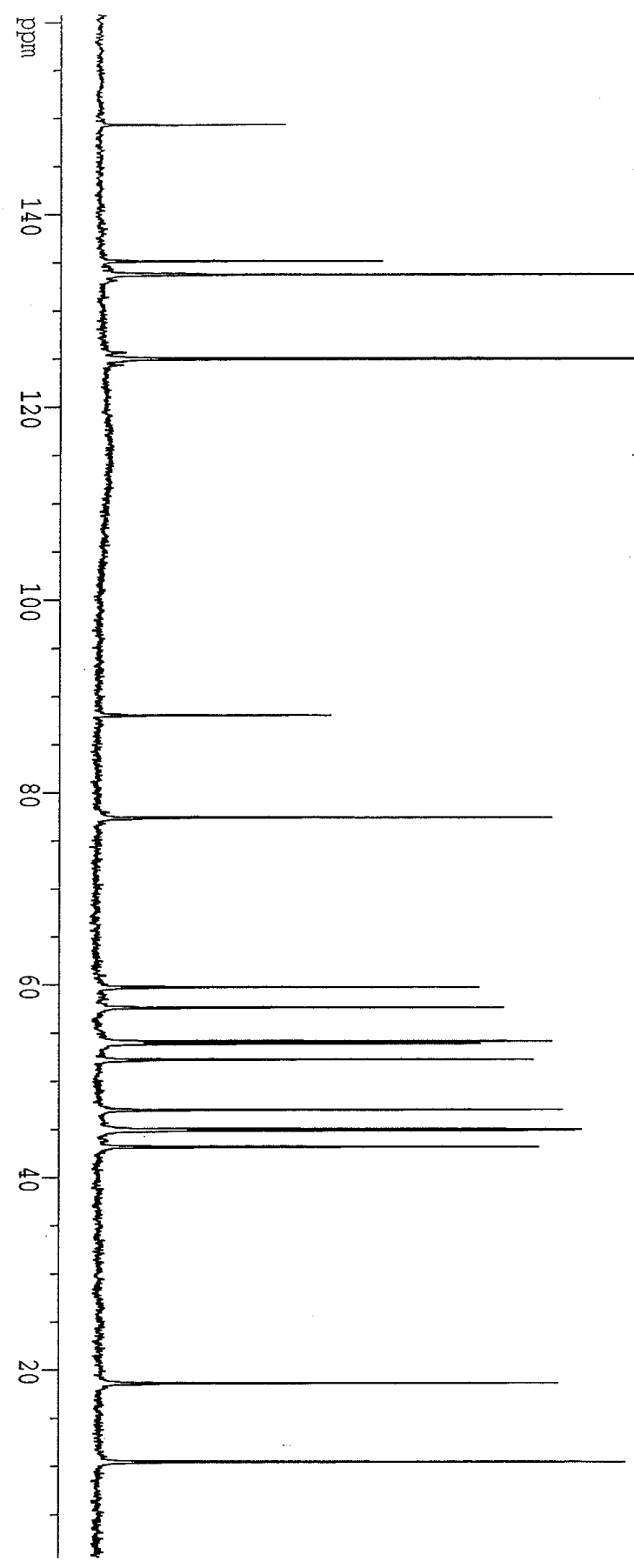
ppm

\section{Compound 12}

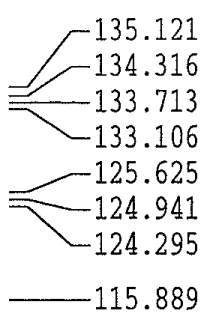

88.006

77.315

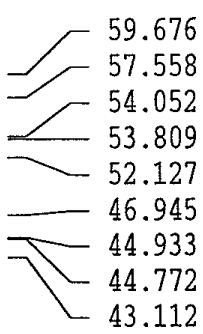

18.538

10.373

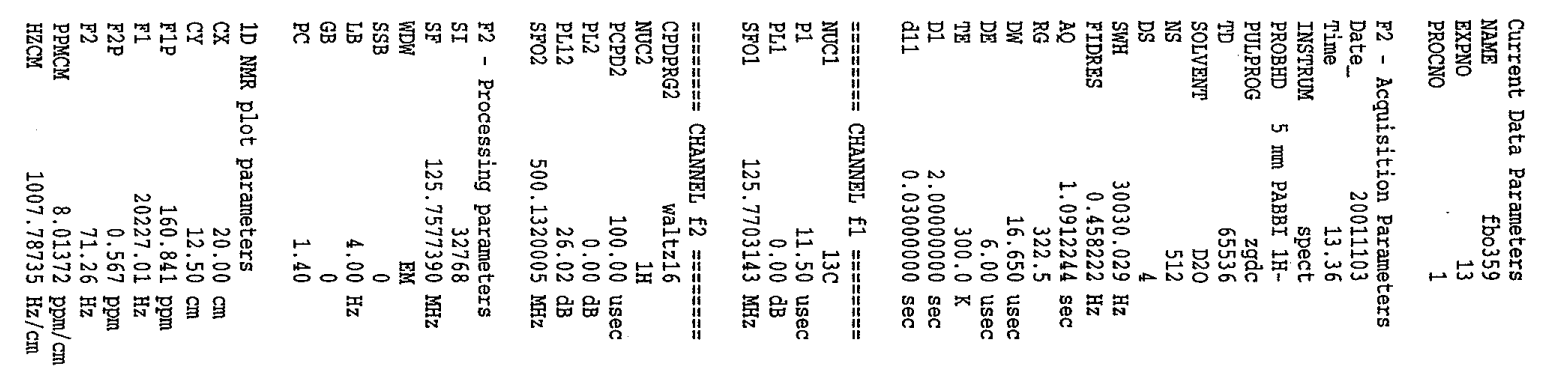



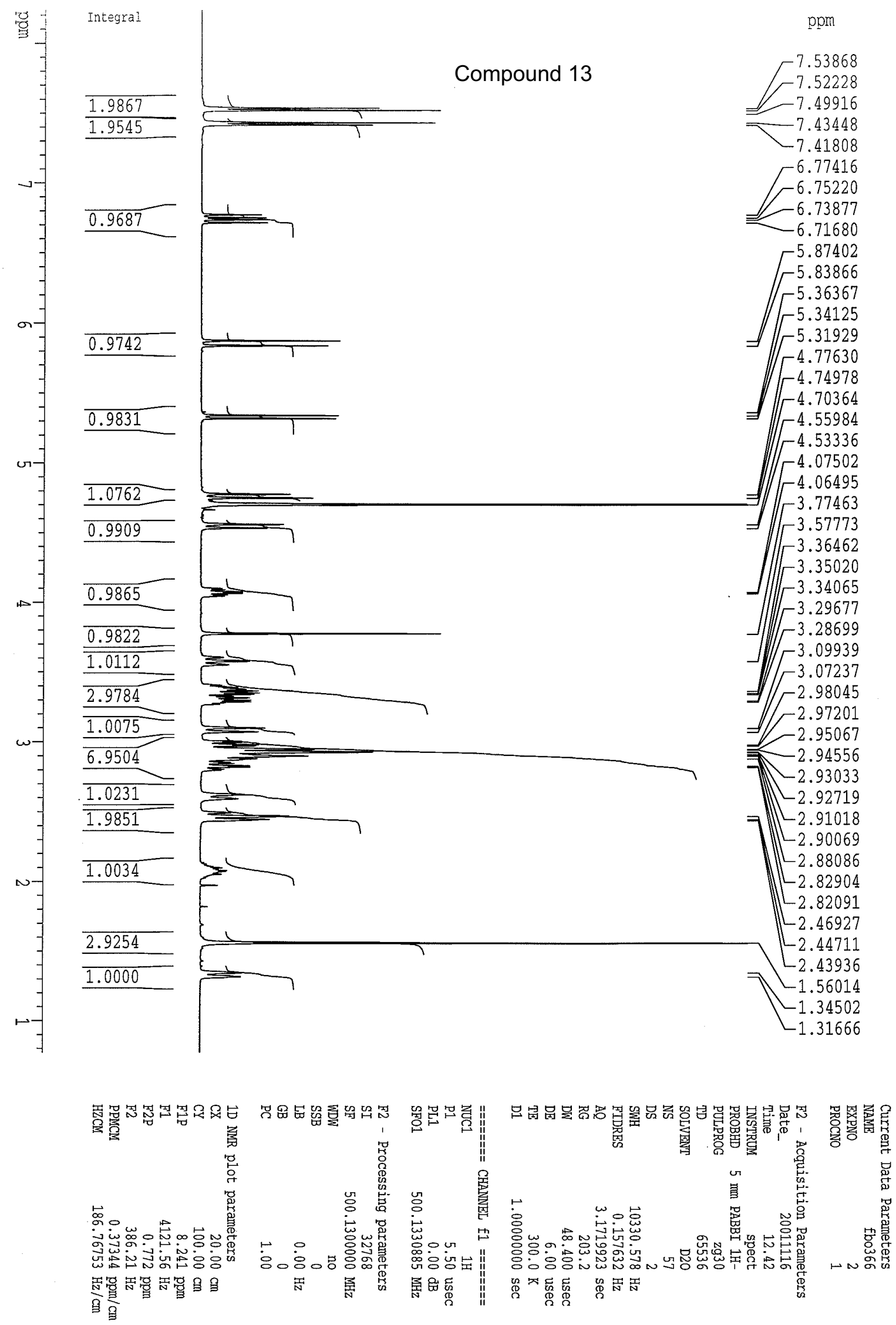


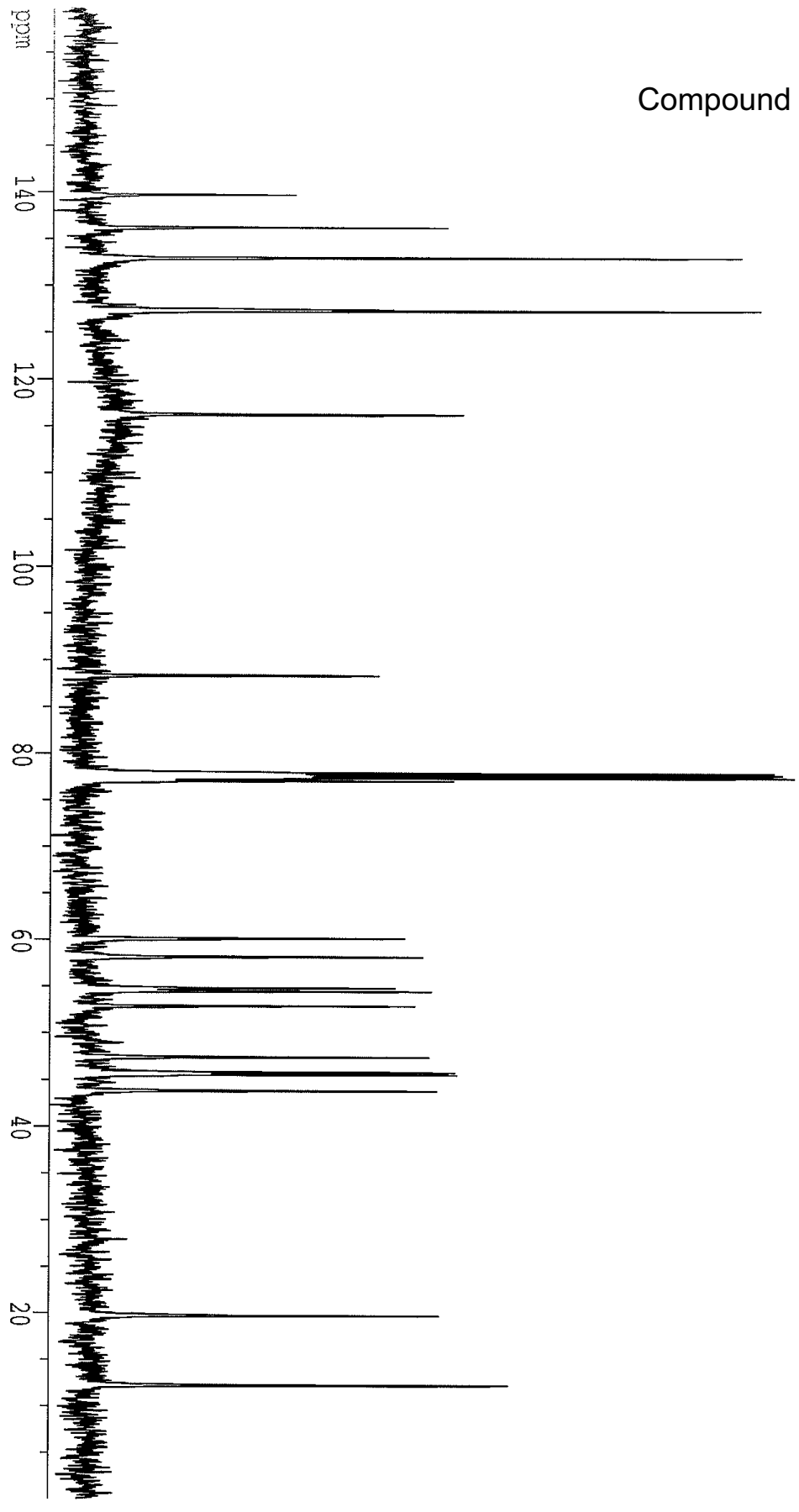

\section{Compound 13}
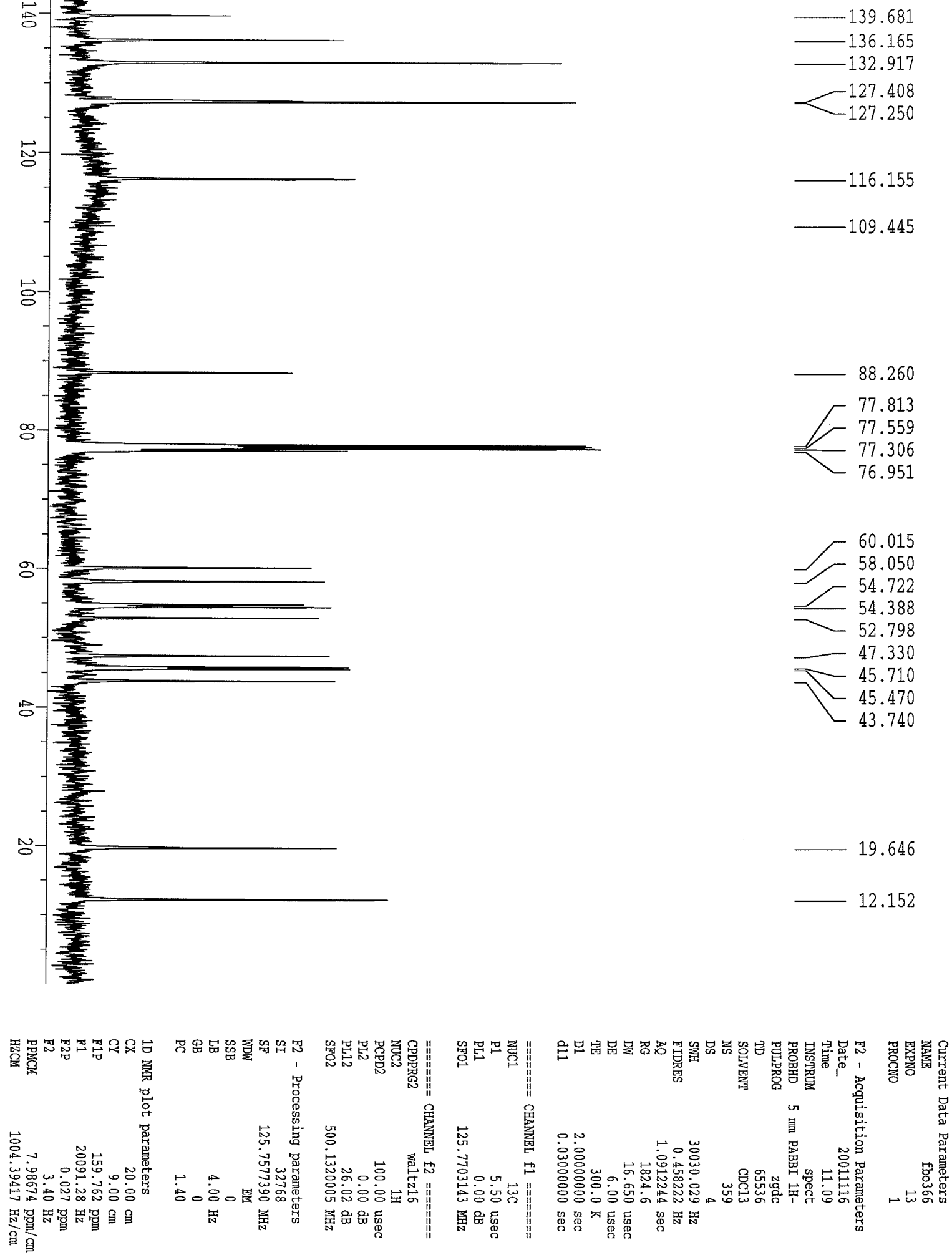

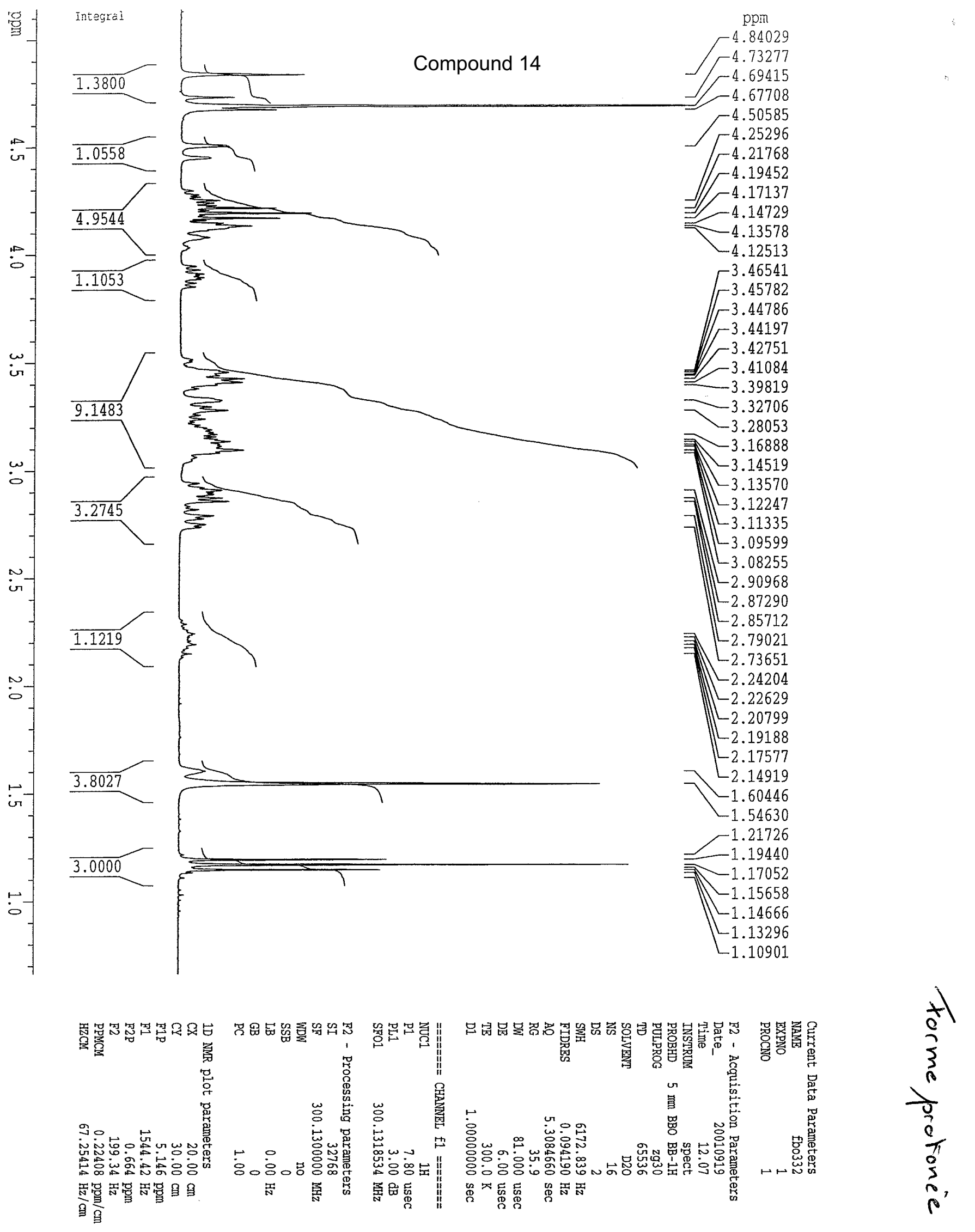


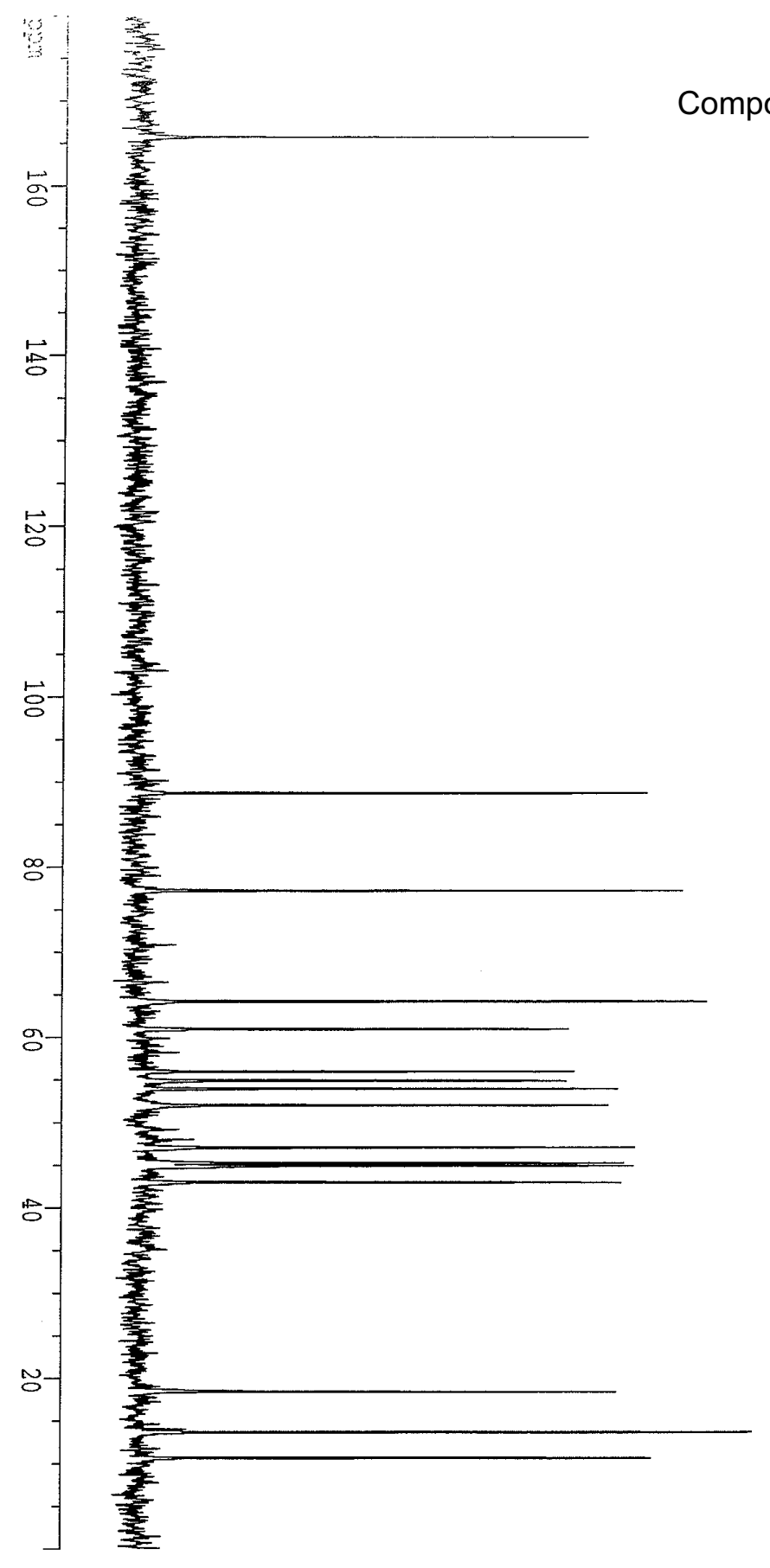

\section{Compound 14}
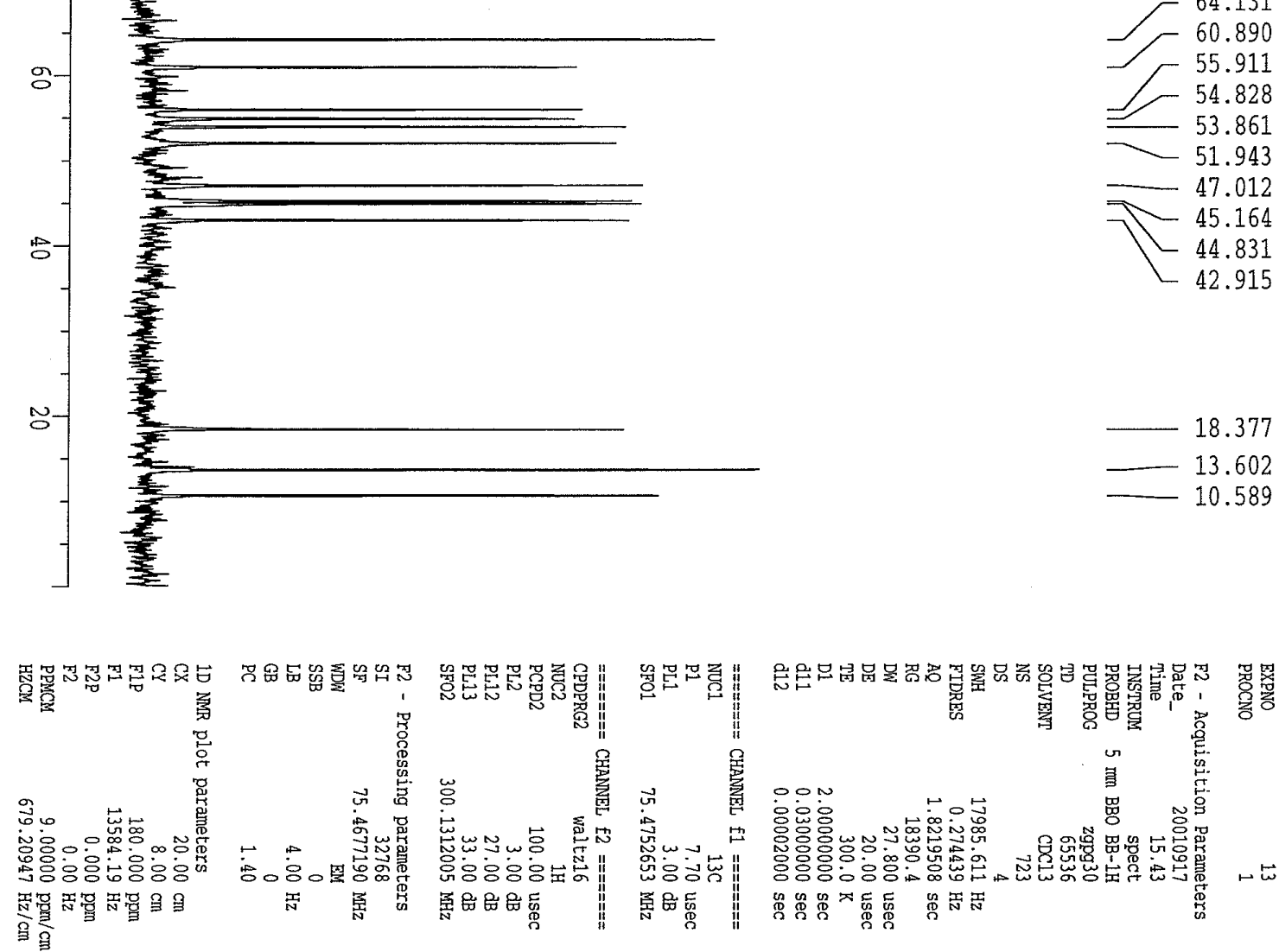

18.377

13.602 10.589 

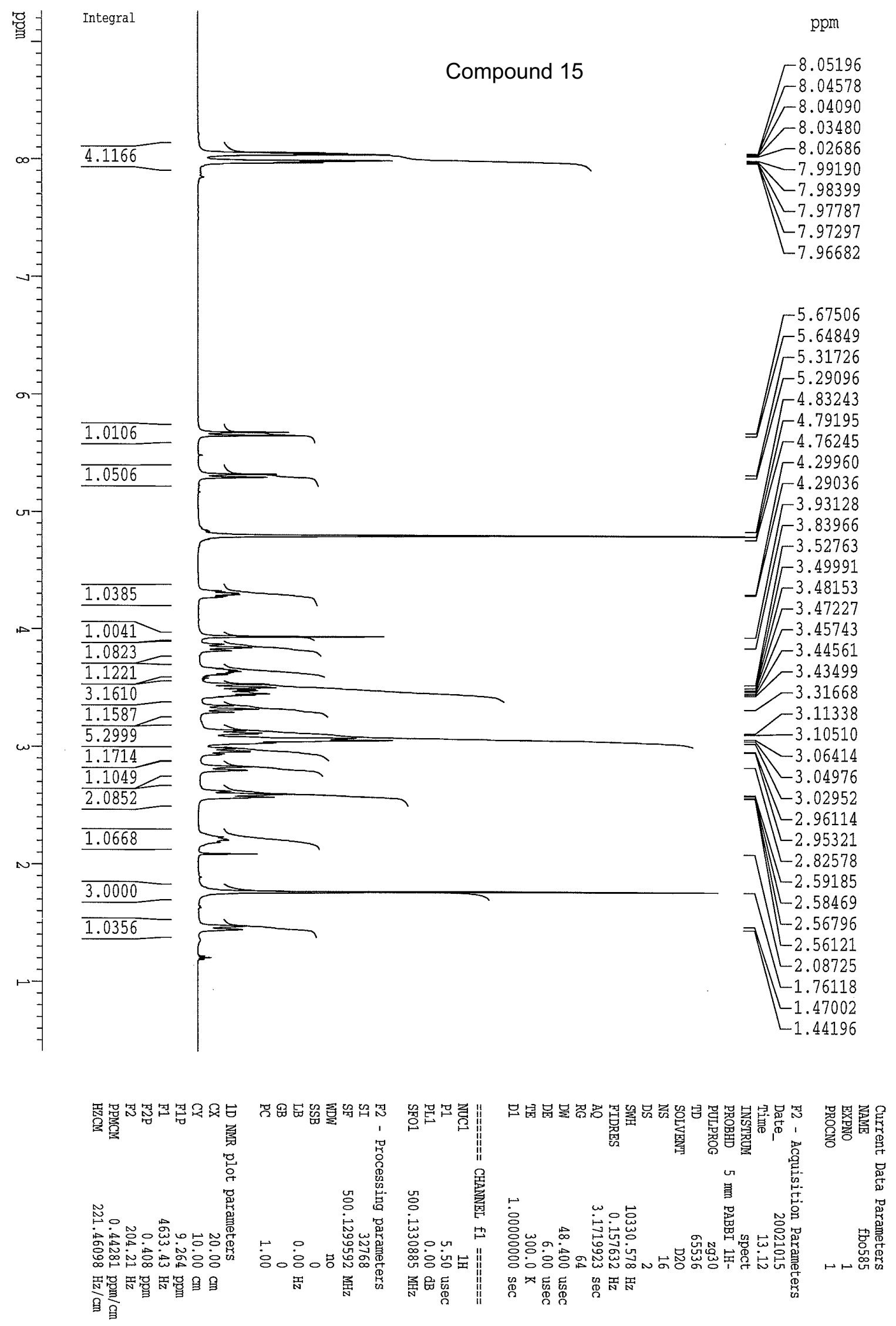


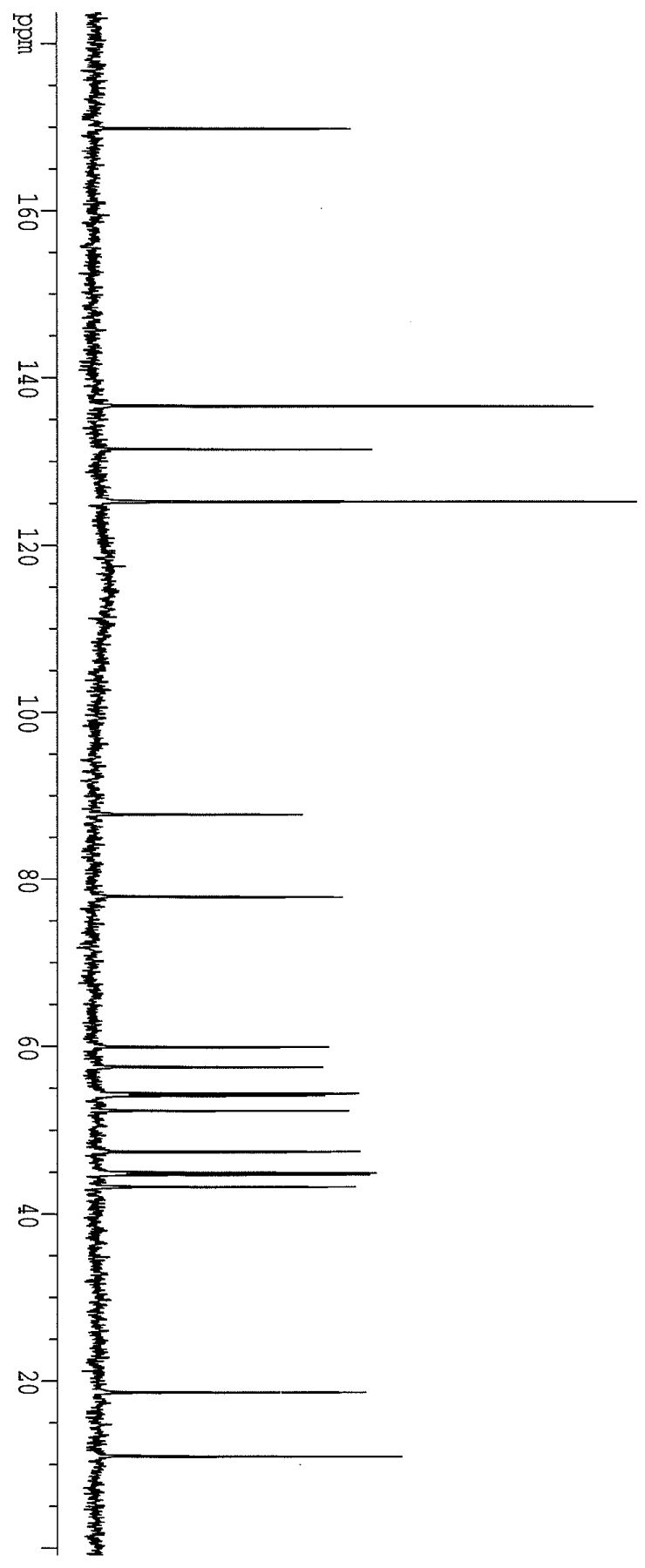

\section{Compound 15}

ppm
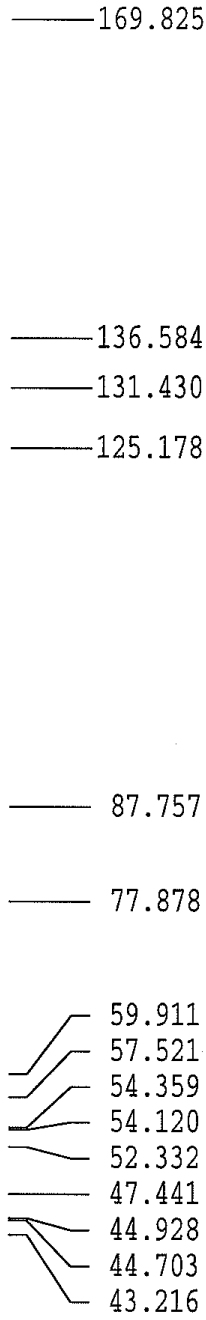

18.673

10.986

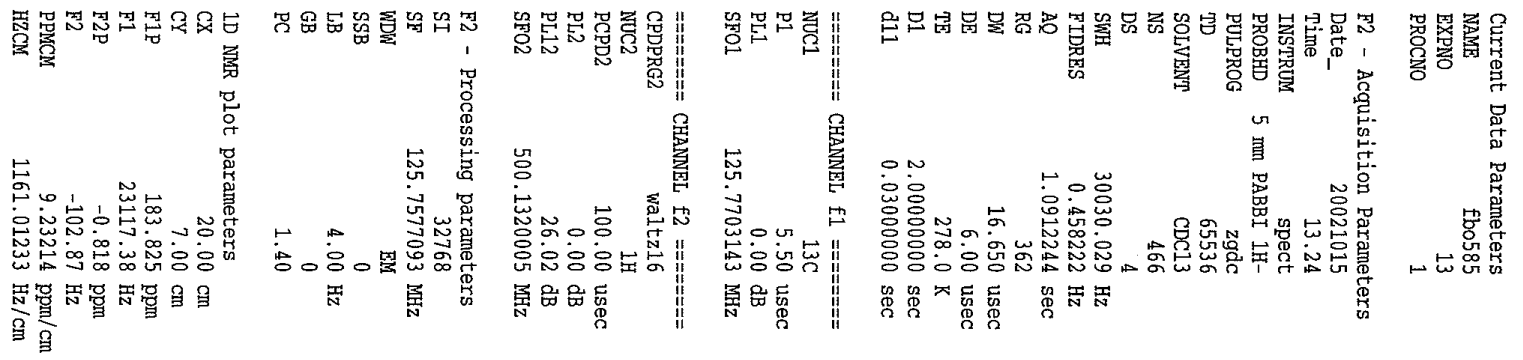

Regioselective $\mathrm{N}$-functionalization of Tetraazacycloalkanes 


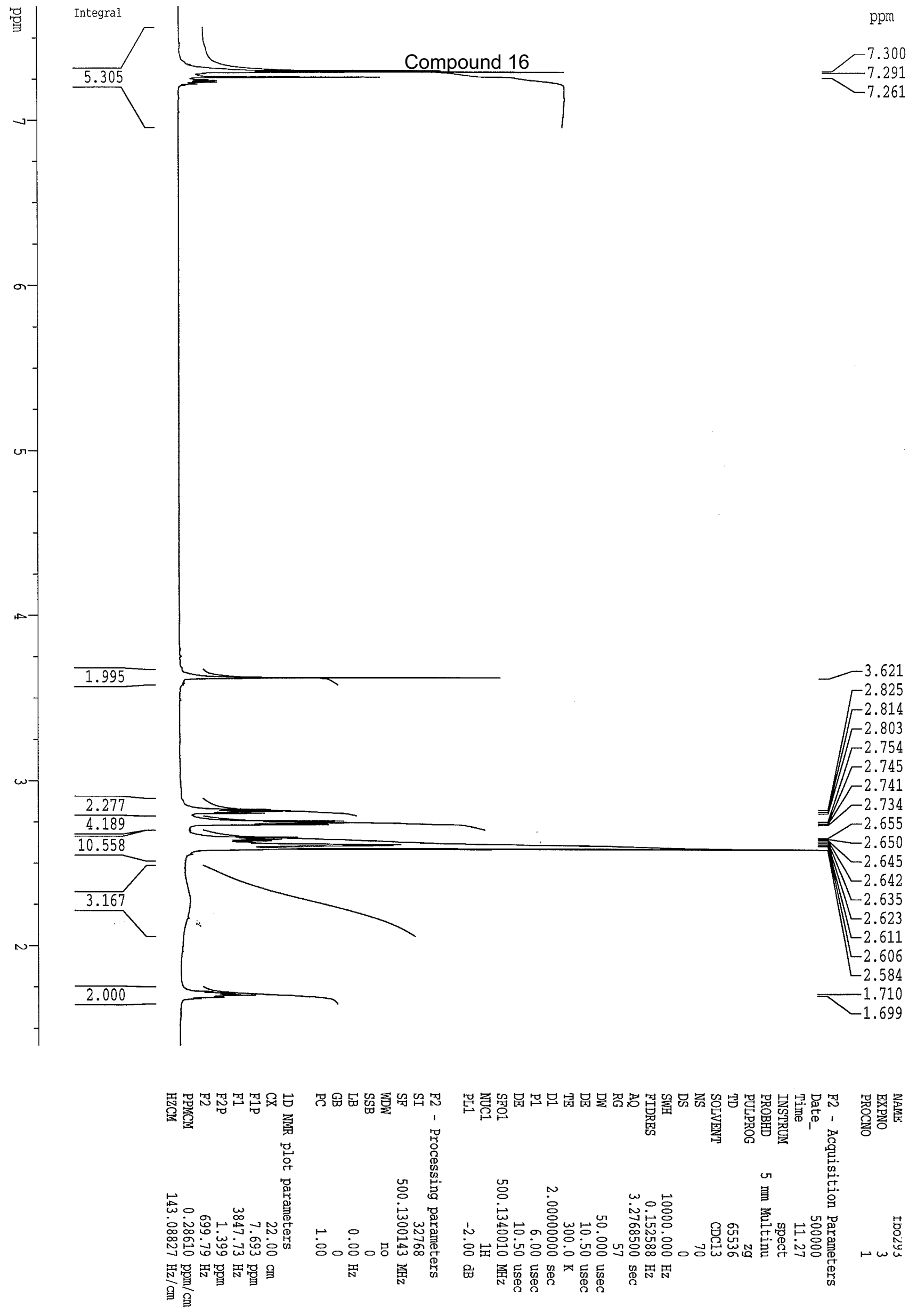



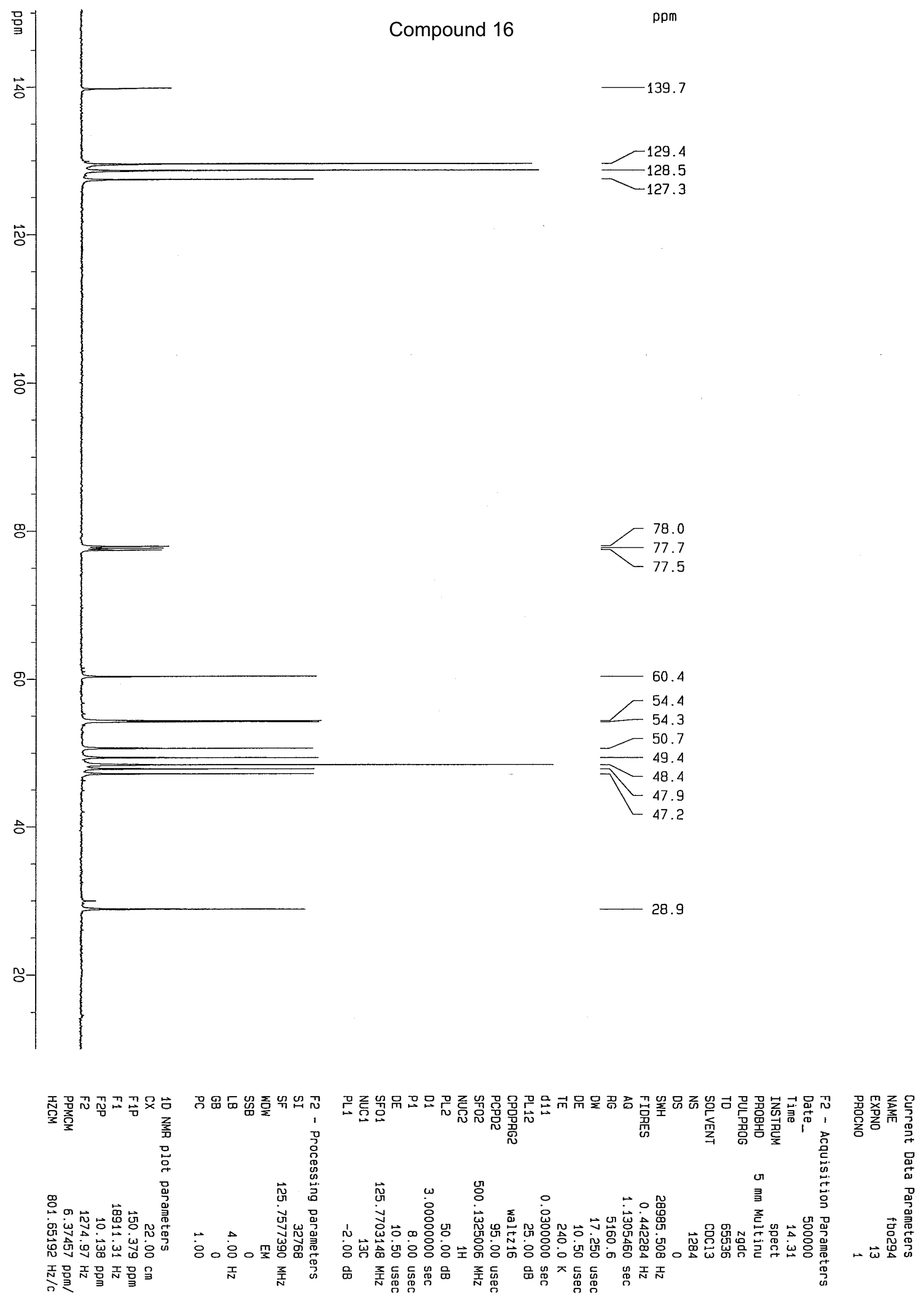

Regioselective N-functionalization of Tetraazacycloalkanes 

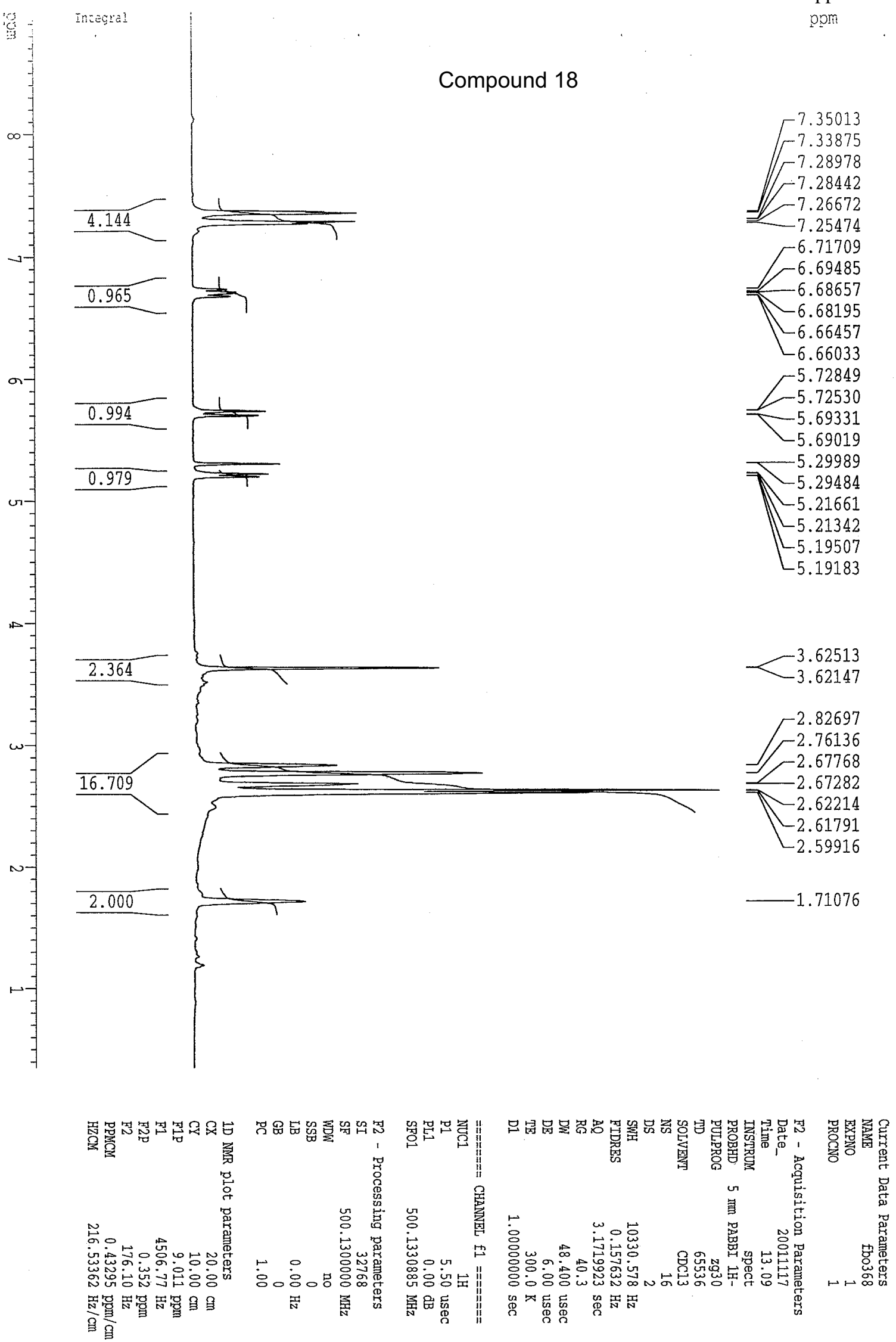


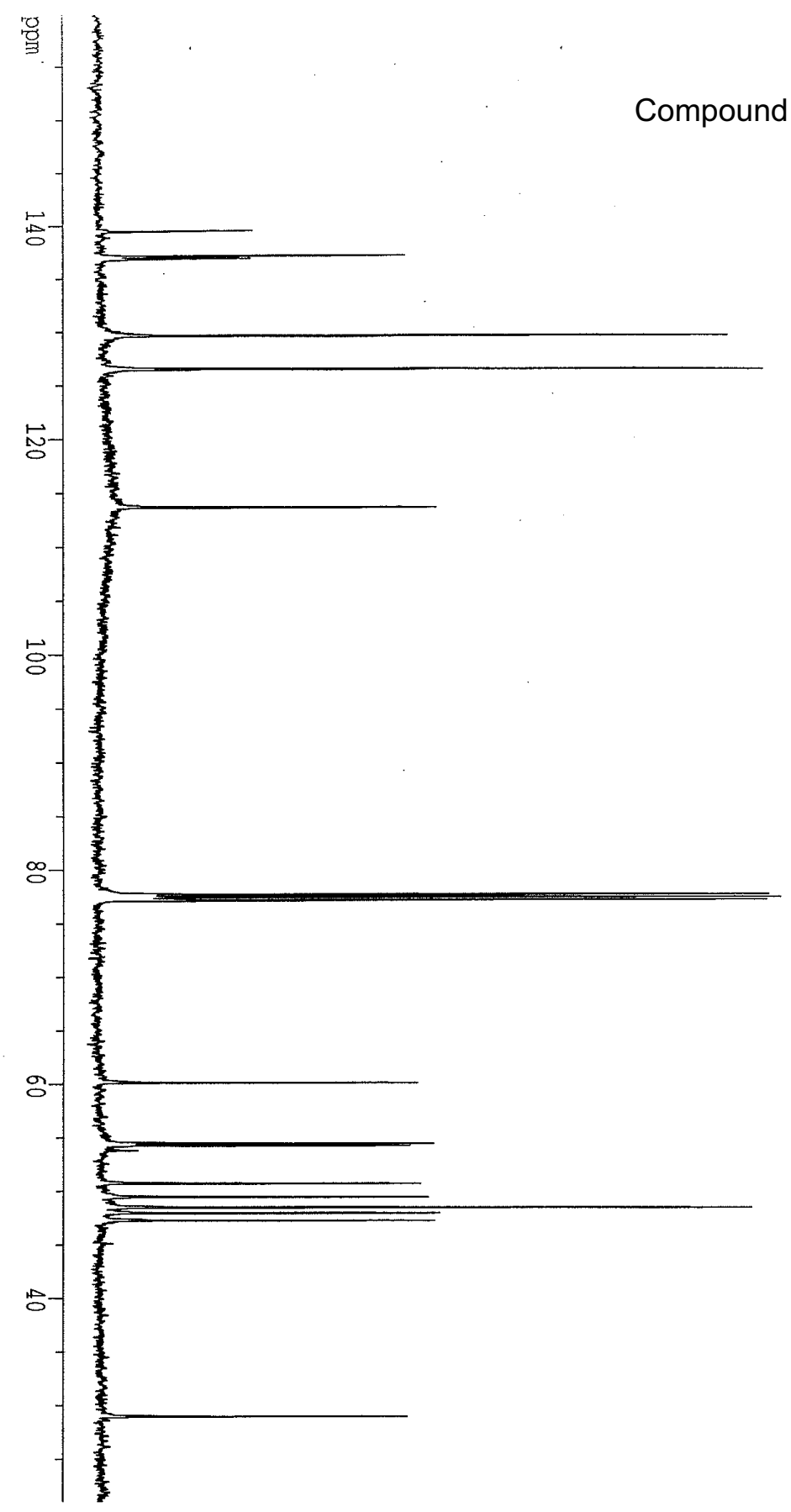

\section{Compound 18}
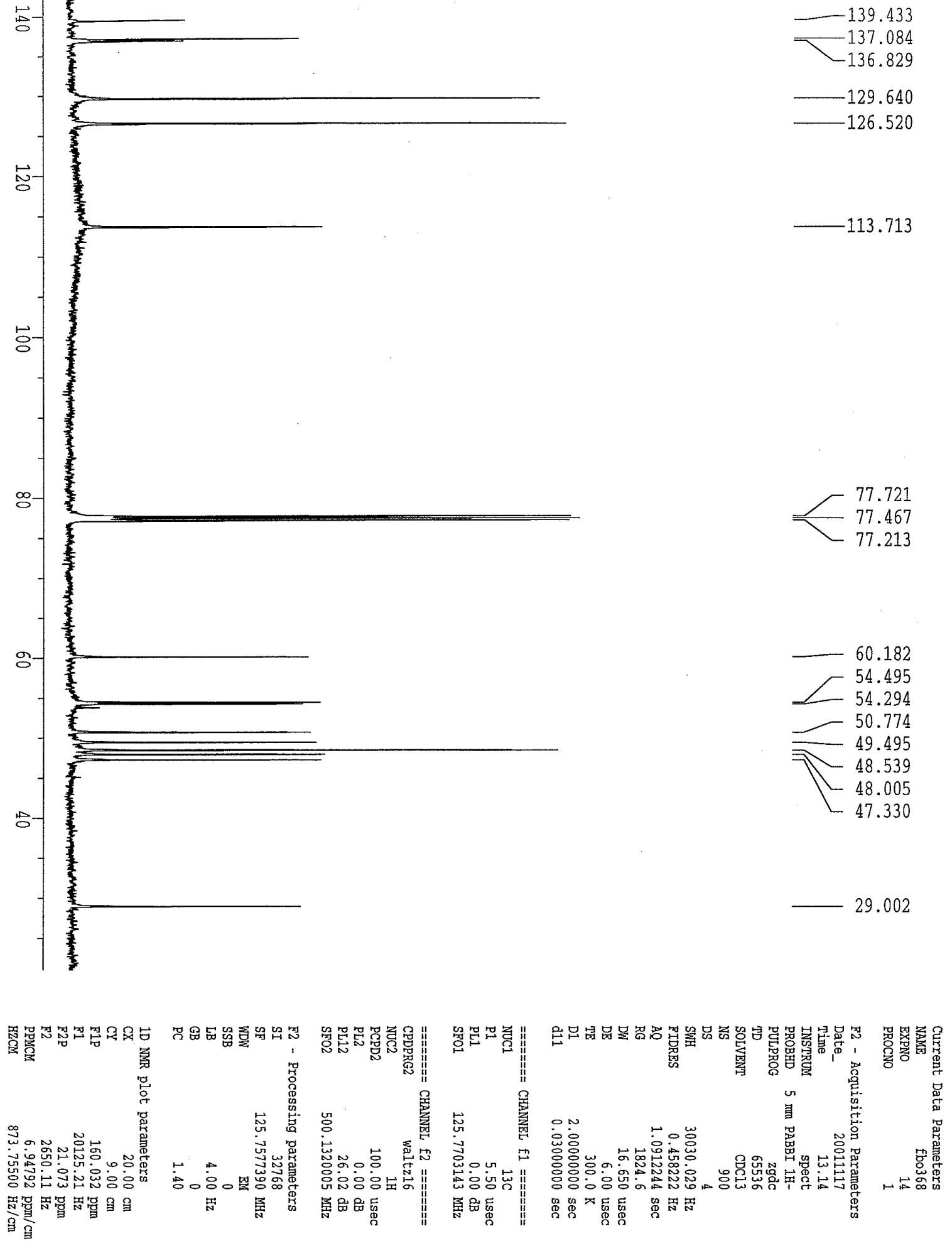

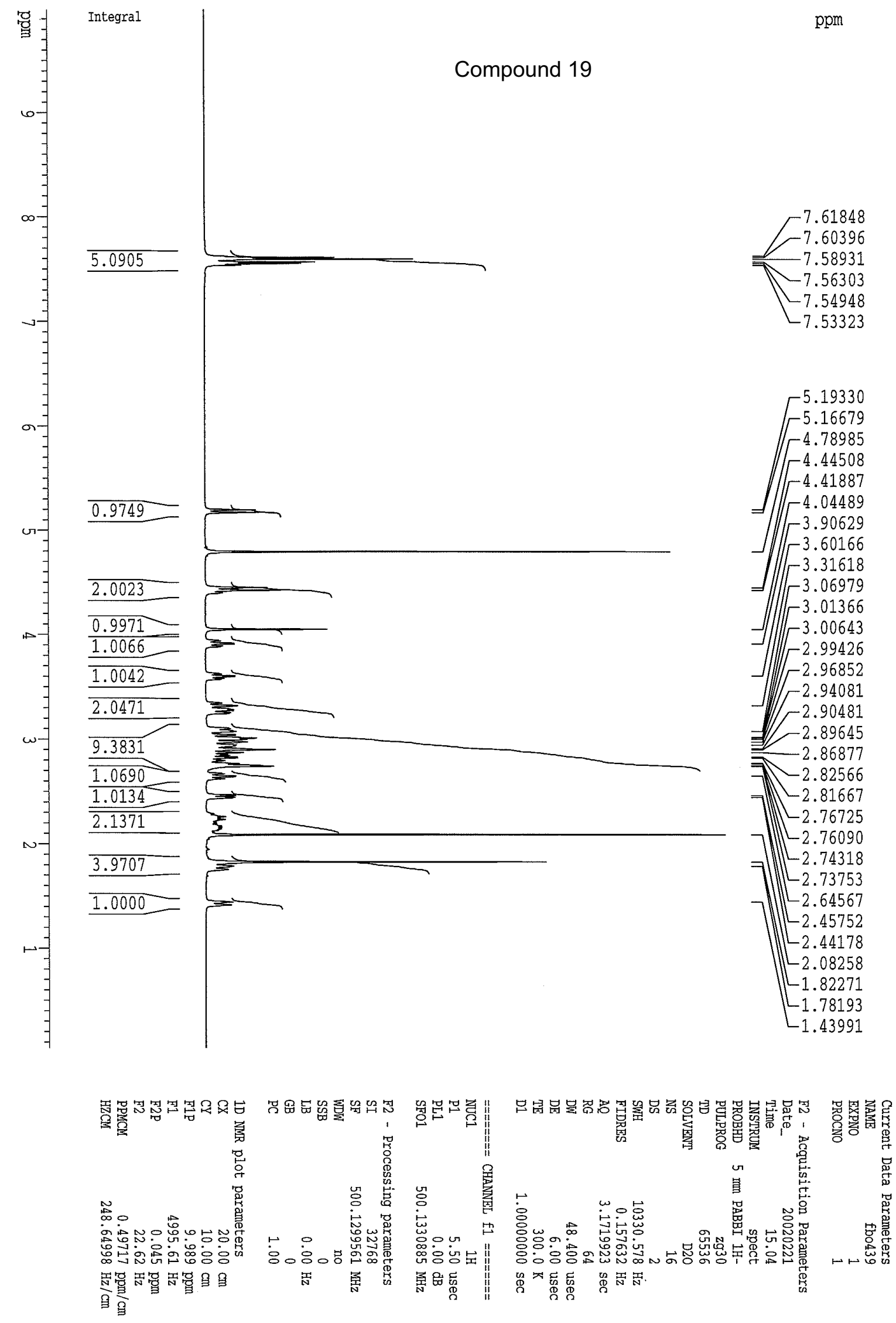


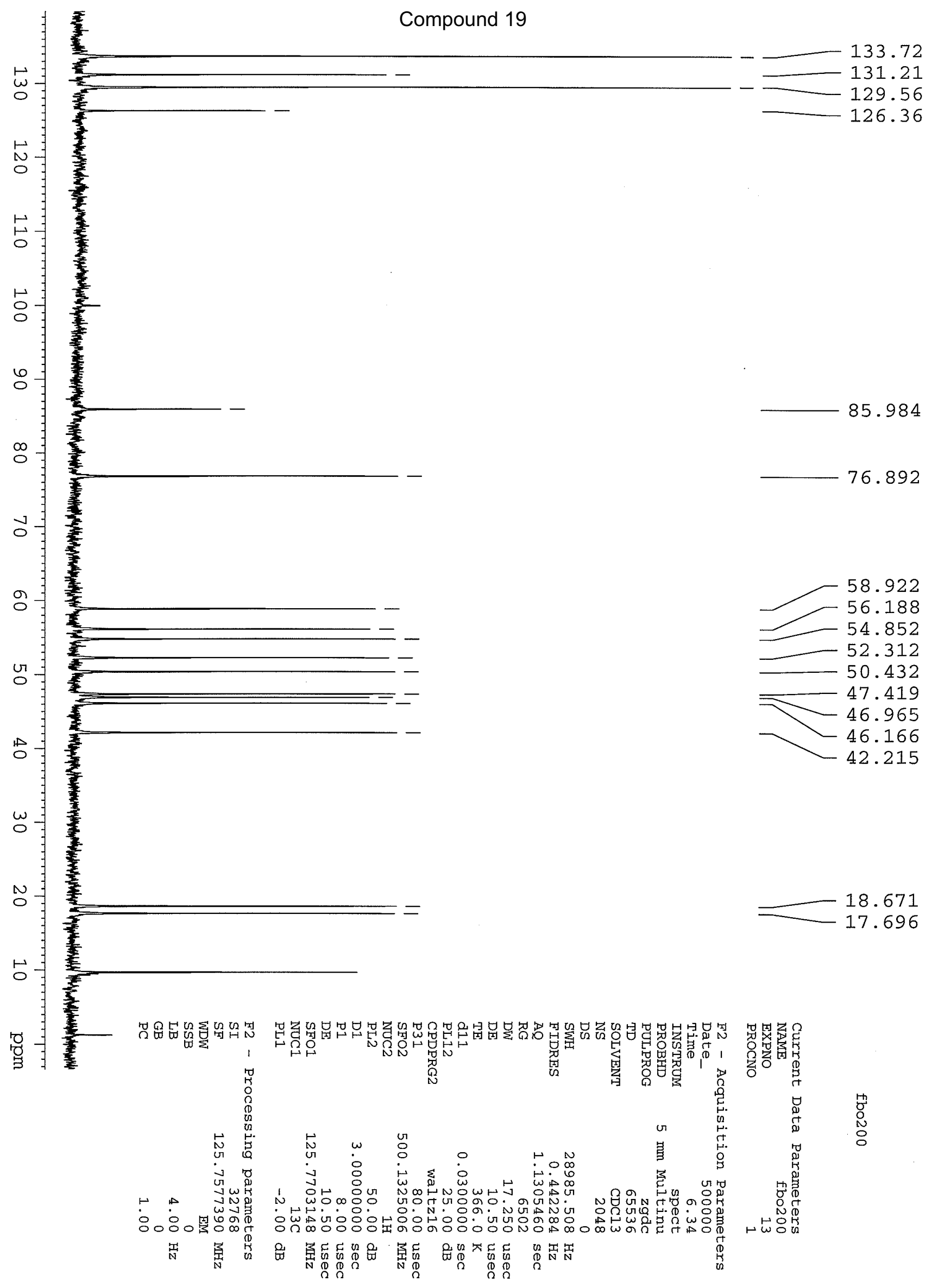

Regioselective N-functionalization of Tetraazacycloalkanes 

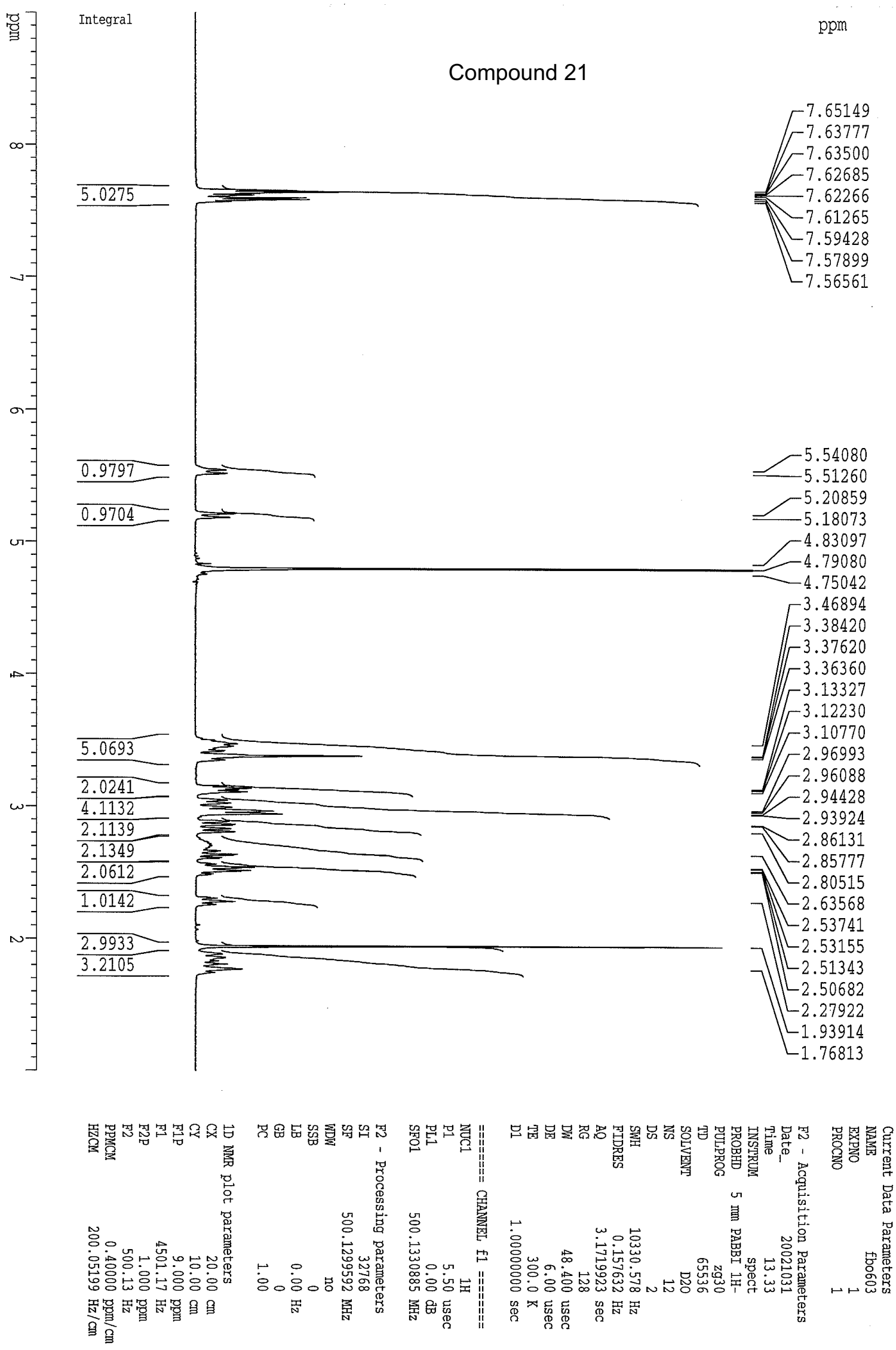

Regioselective N-functionalization of Tetraazacycloalkanes 


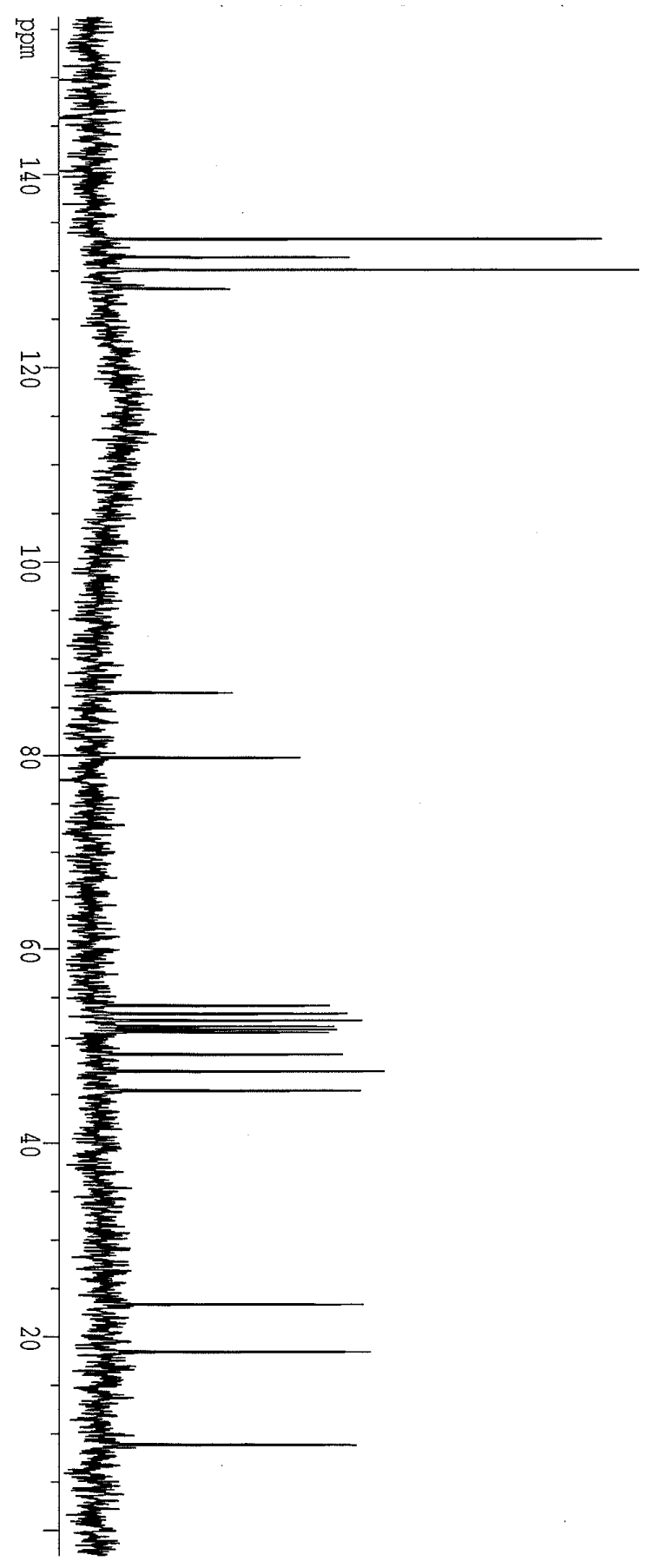

\section{Compound 21}

ppm

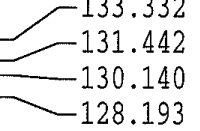

86.542

79.829

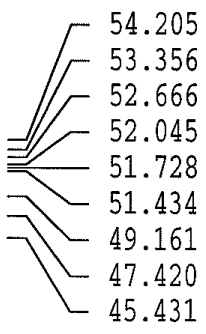

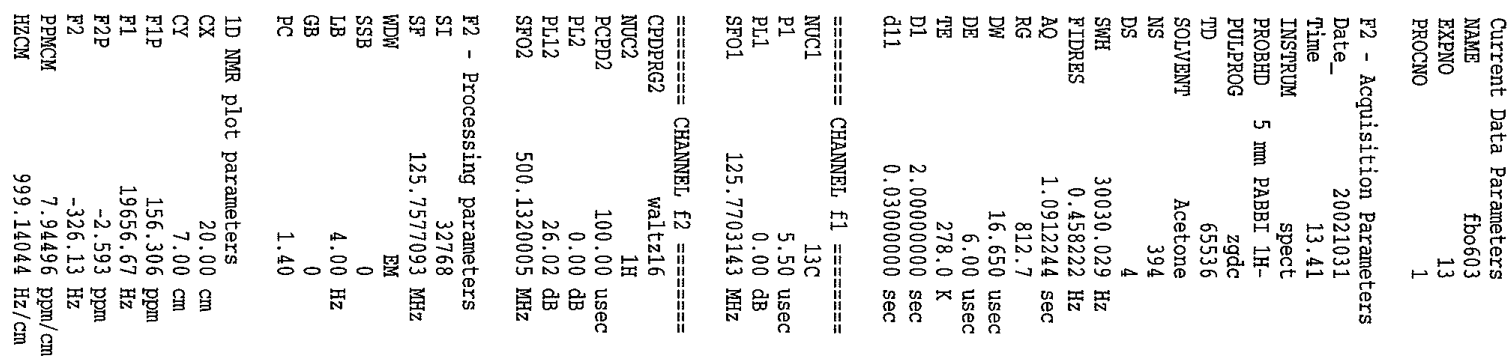



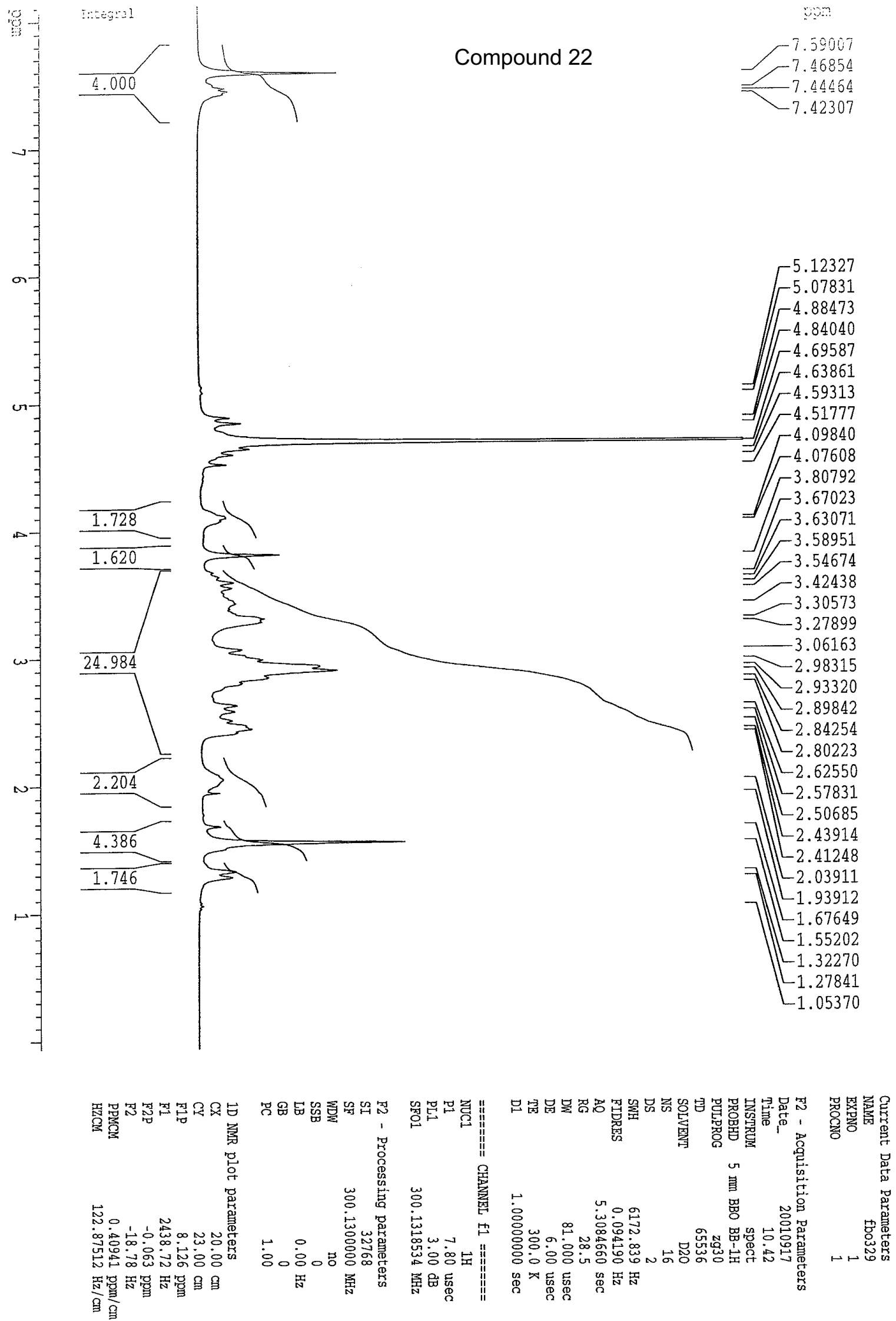

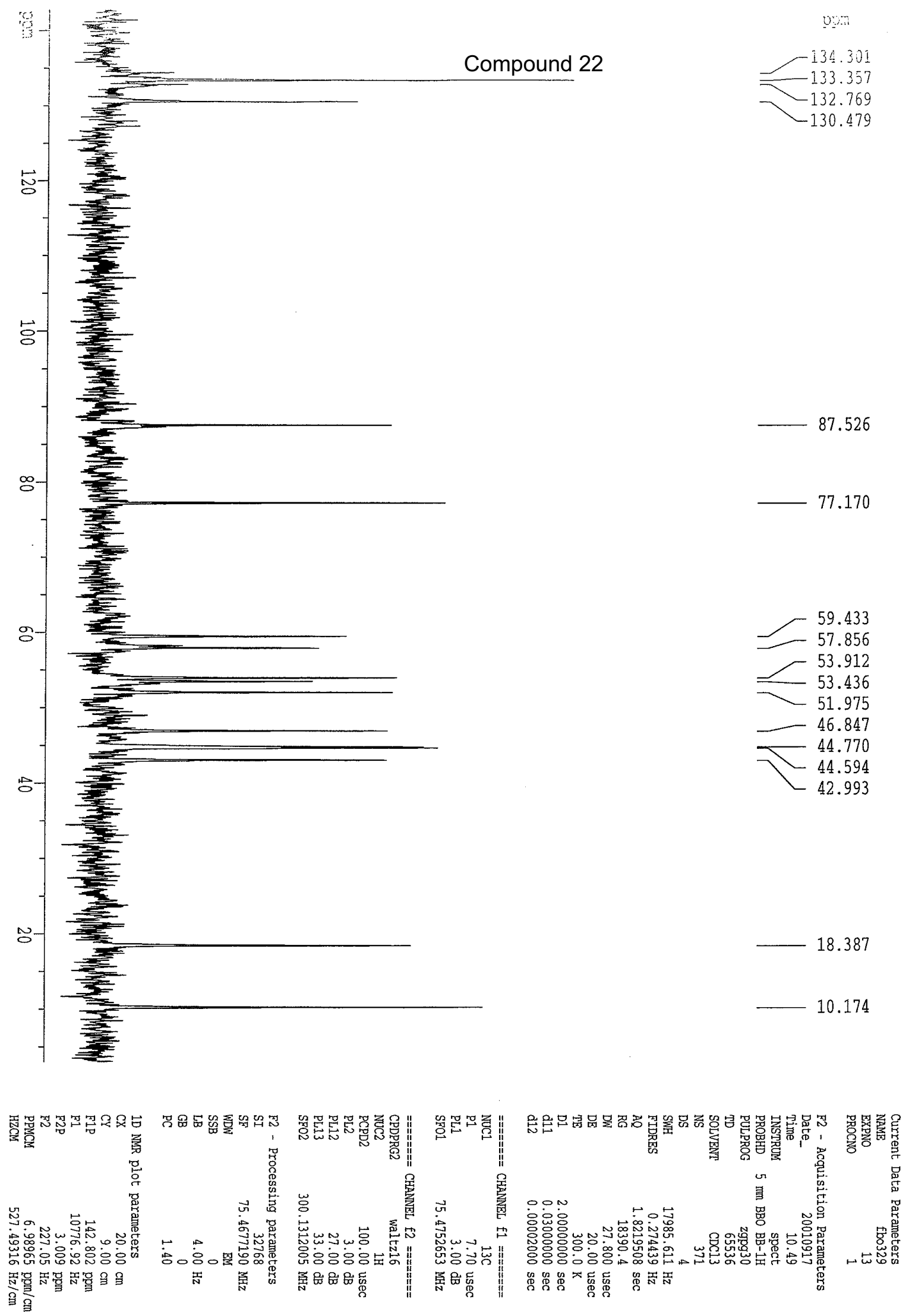

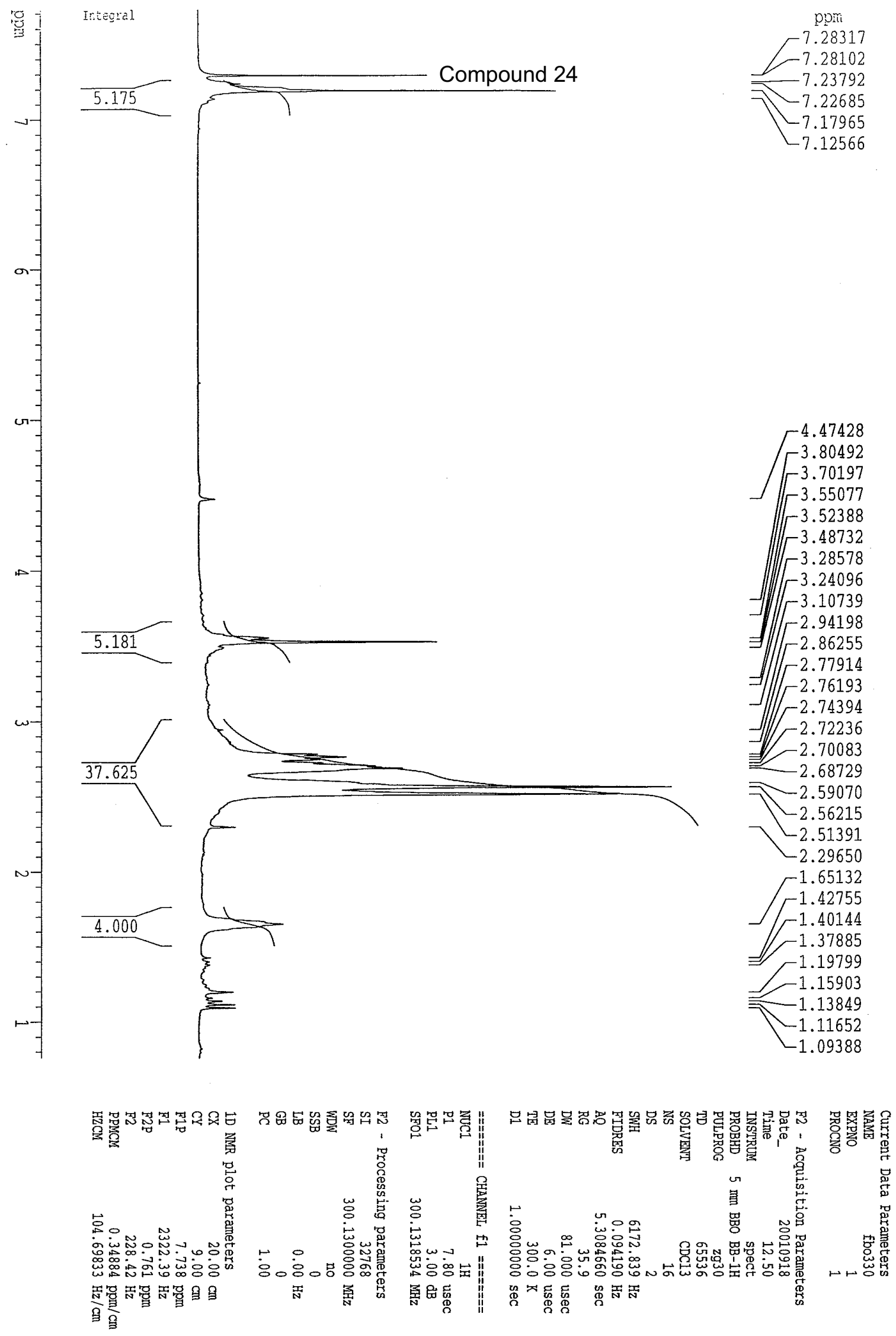


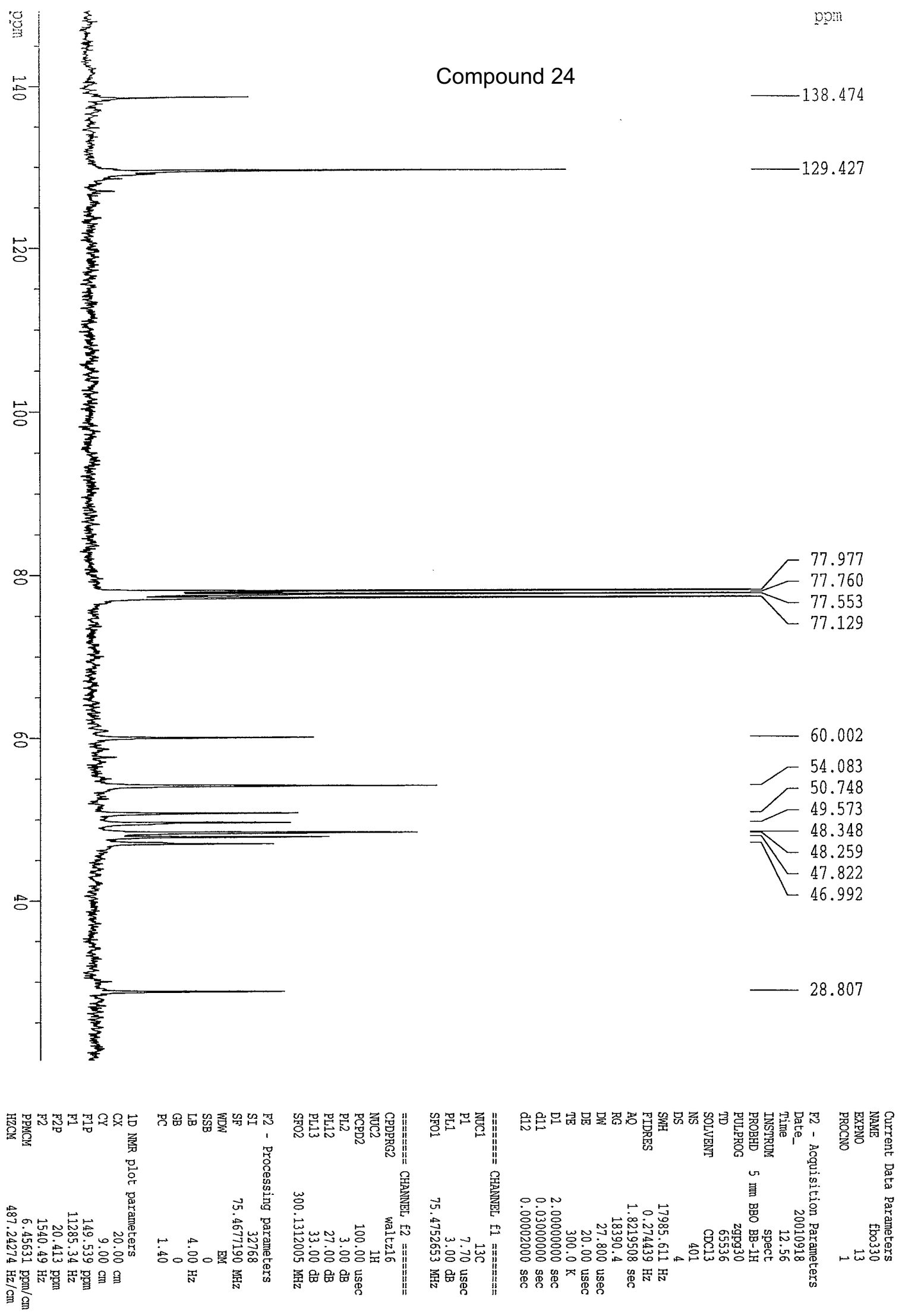

Regioselective N-functionalization of Tetraazacycloalkanes 


\section{Compound 26}
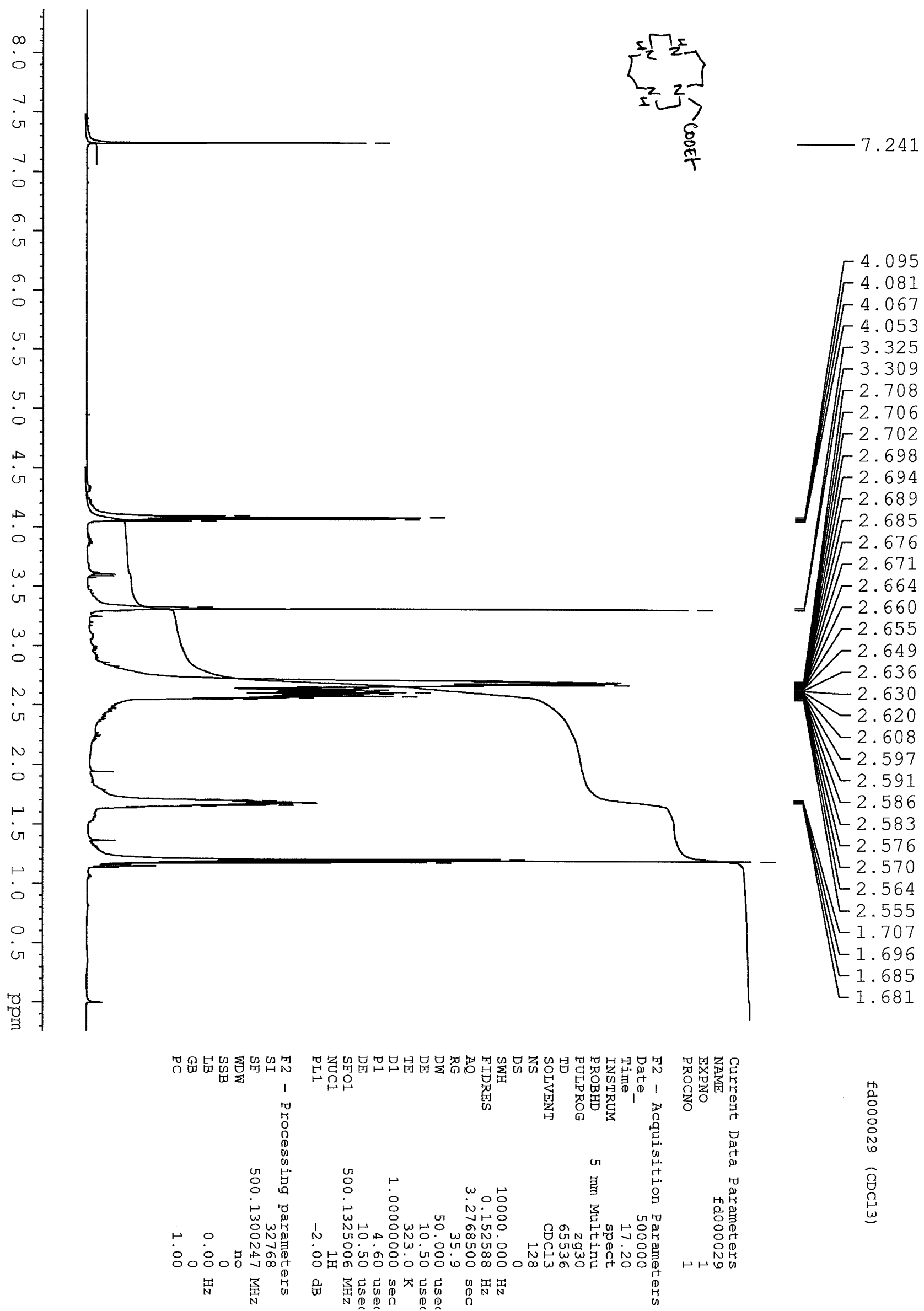

Regioselective $\mathrm{N}$-functionalization of Tetraazacycloalkanes 


\section{Compound 26}

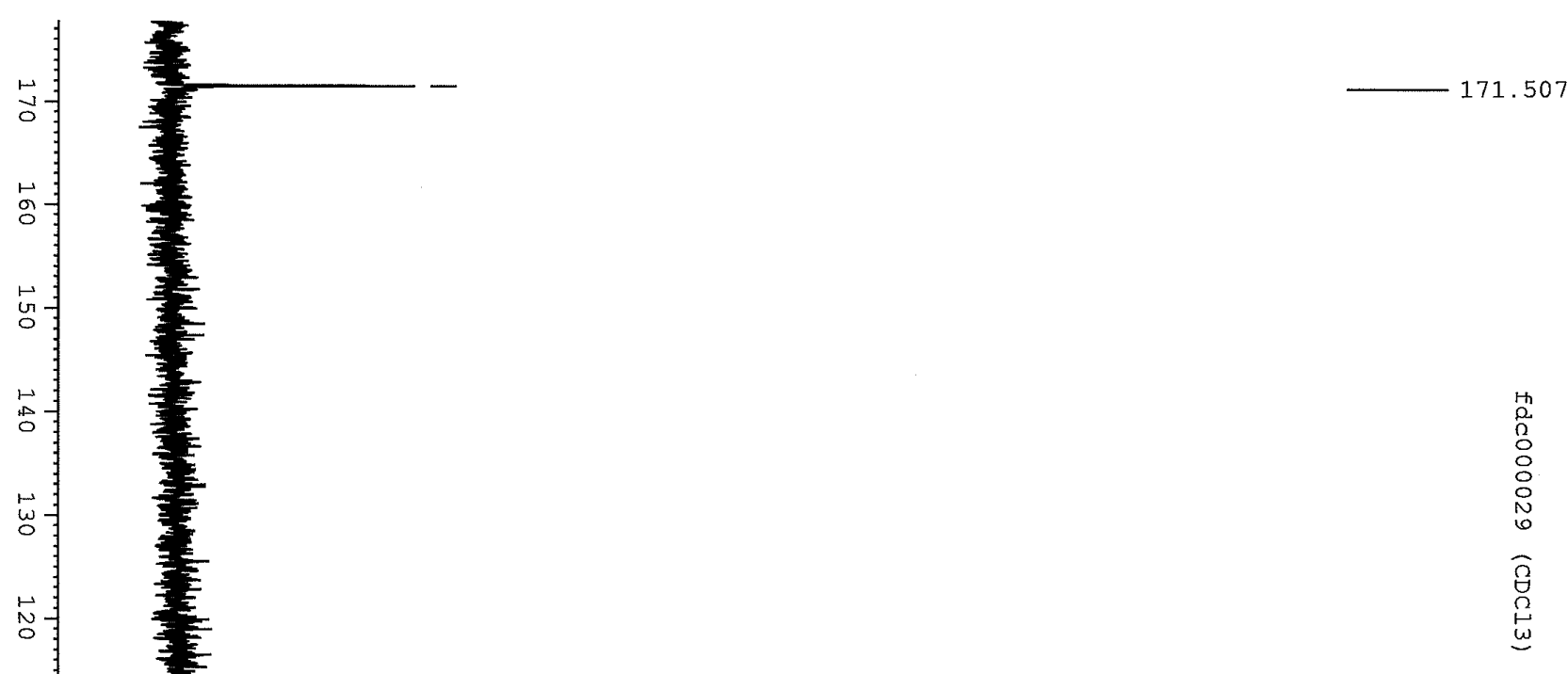

它

용.

$:$

$\stackrel{\infty}{\circ}$

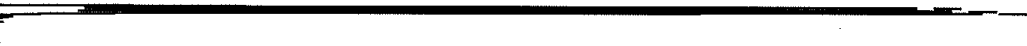

$-77.720$

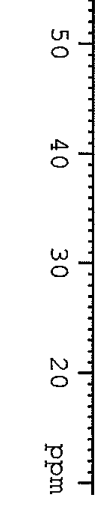

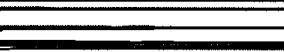




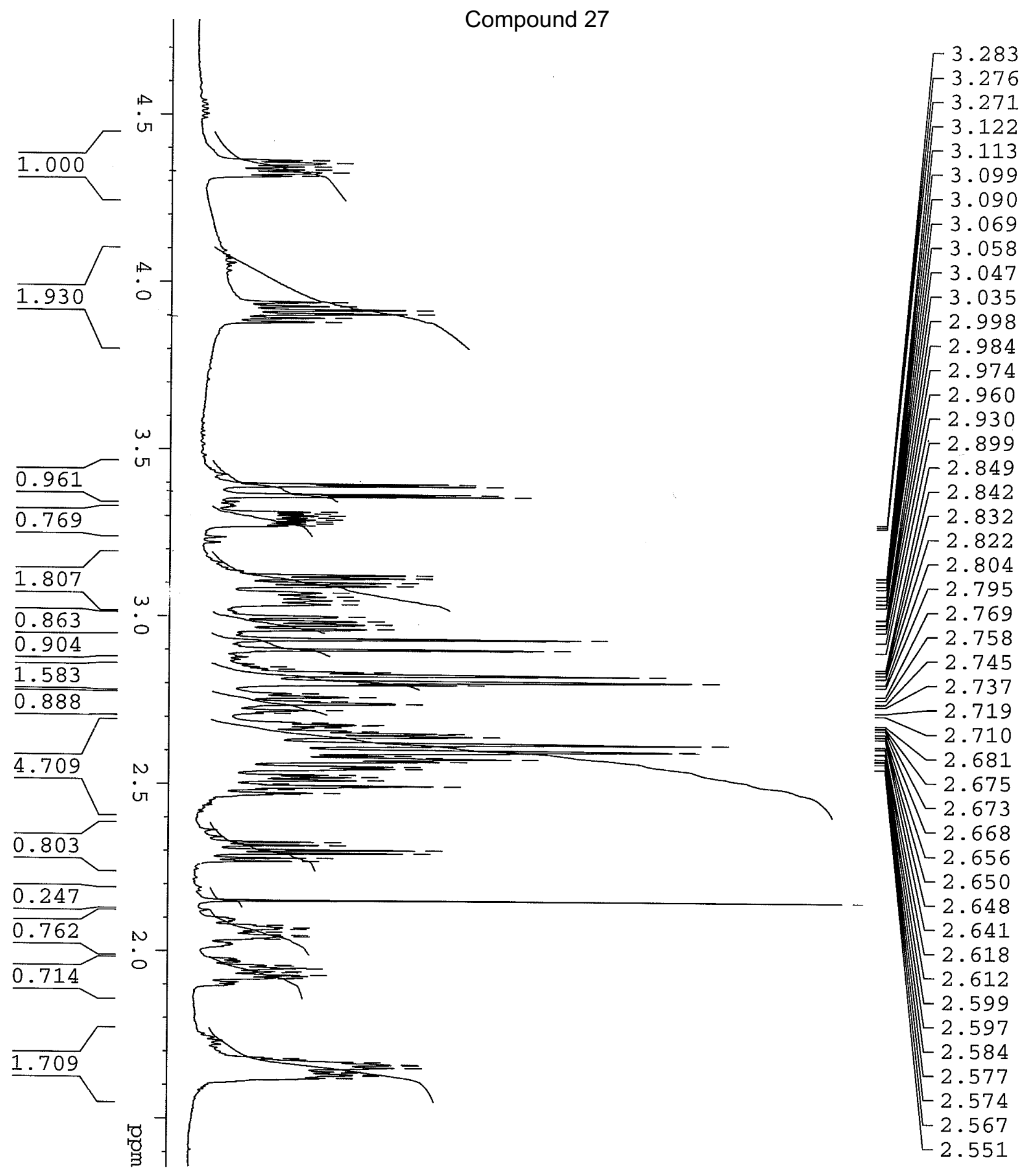

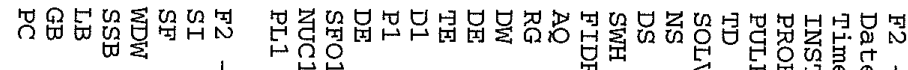

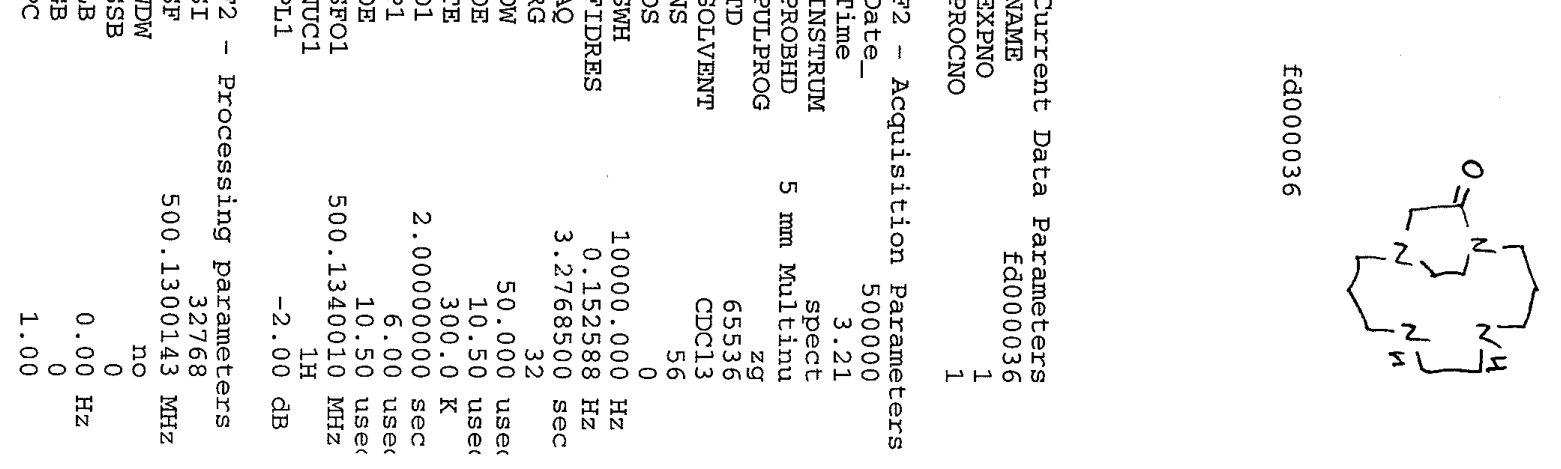

Regioselective $\mathrm{N}$-functionalization of Tetraazacycloalkanes 


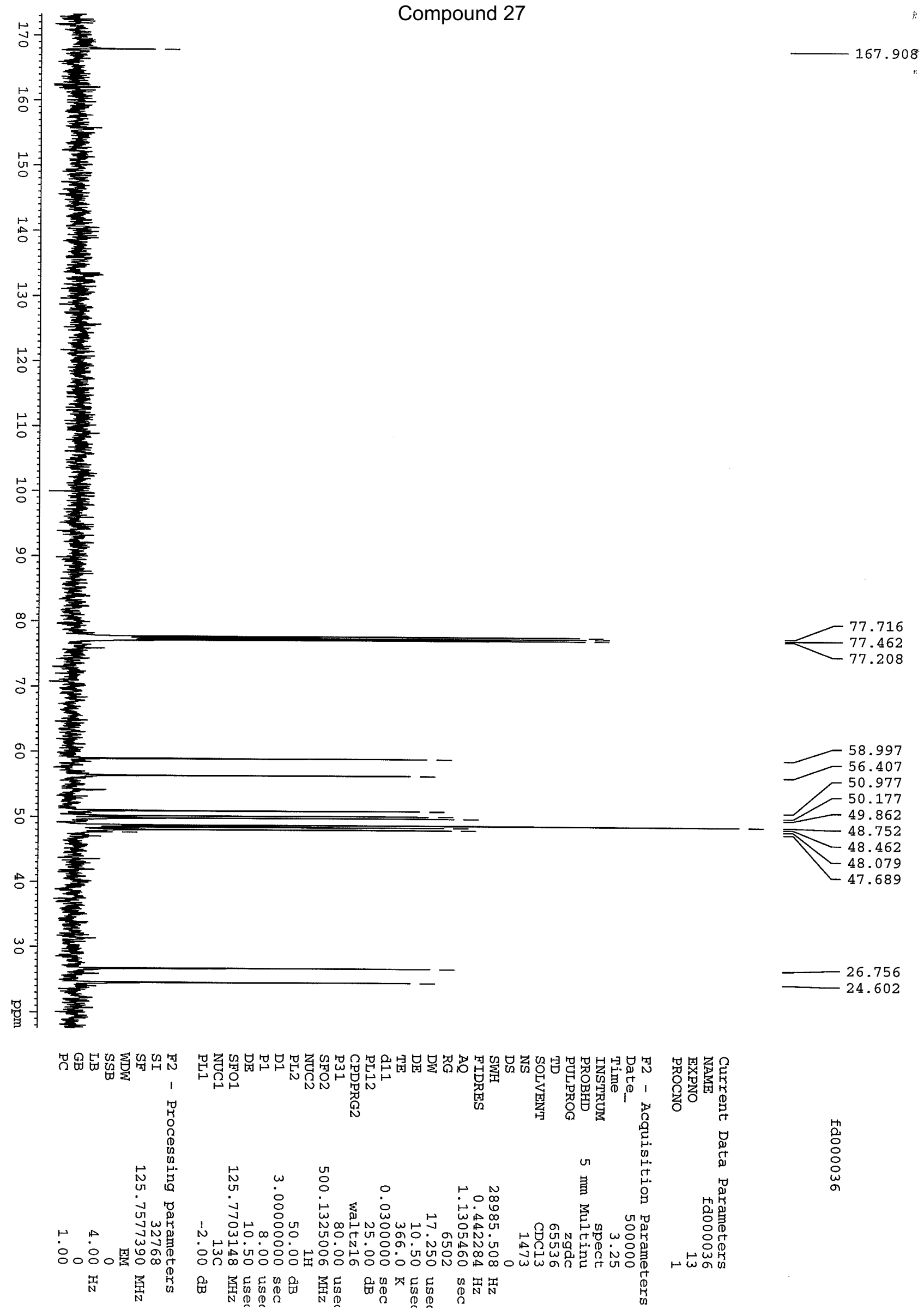

Regioselective N-functionalization of Tetraazacycloalkanes 

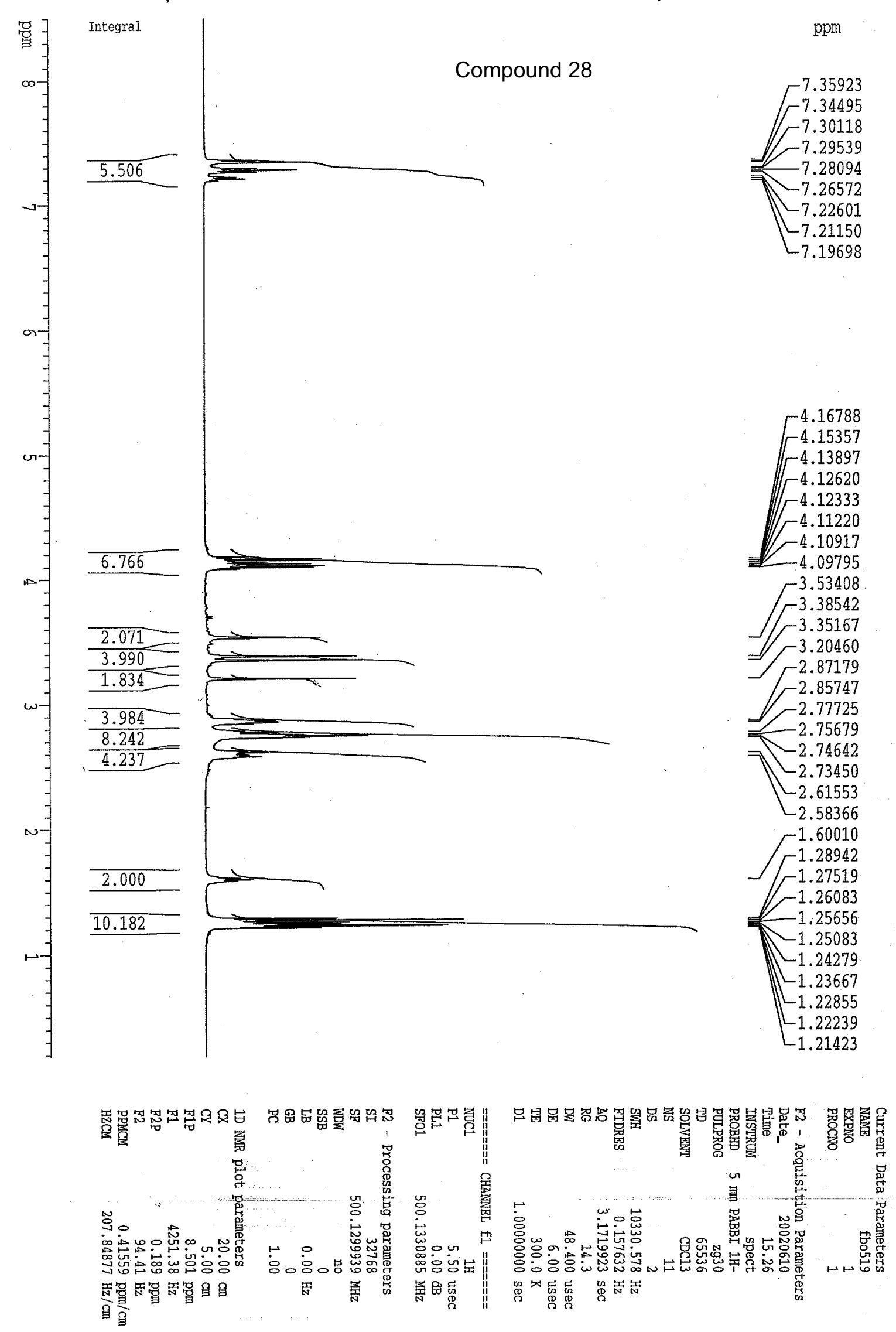


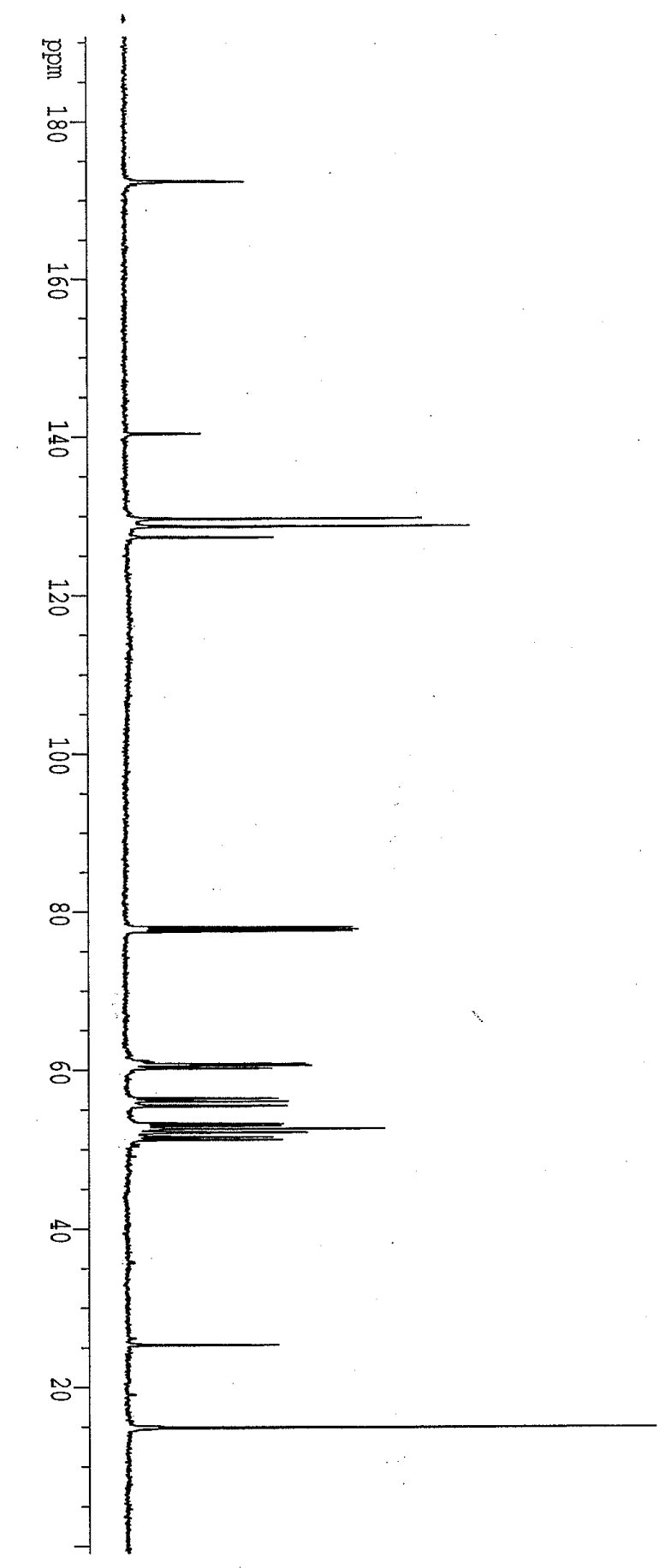

Compound 28

ppm

$-140.363$

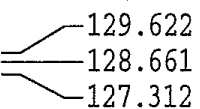

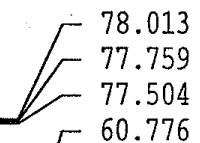

F 60.675

- 60.581

- 60.225

$-56.416$

$-56.085$

$-55.468$

$\longrightarrow 53.235$

$-52.925$

$-52.606$

$-52.158$

$\leftarrow 52.093$

$\leftarrow 51.563$

ᄂ 51.220

$-25.333$

14.926

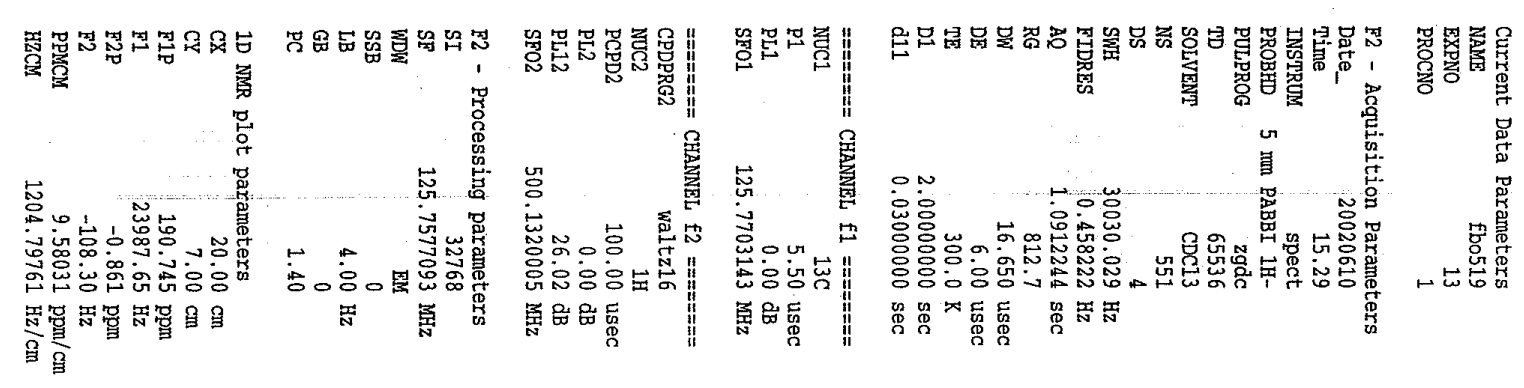

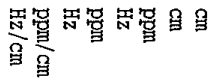



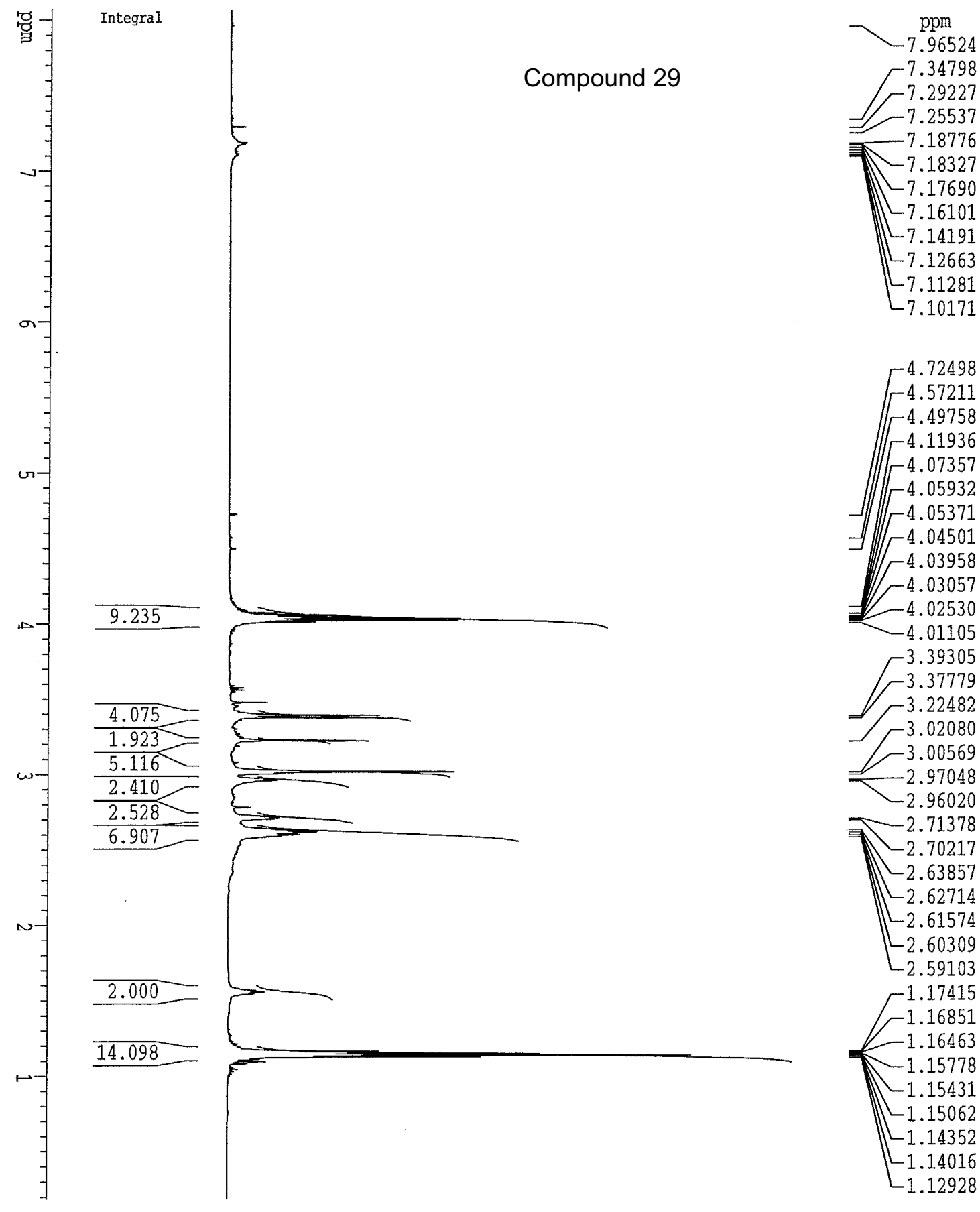

3.39305

3.37779
-3.22482

3.02080

$-3.00569$

$-2.97048$

$-2.96020$

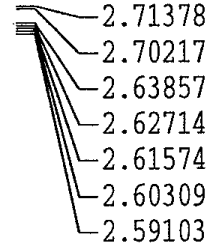

1.17415
-1.16851
-1.16463
-1.15778
-1.15431
-1.15062
1.14352
1.14016
1.12928

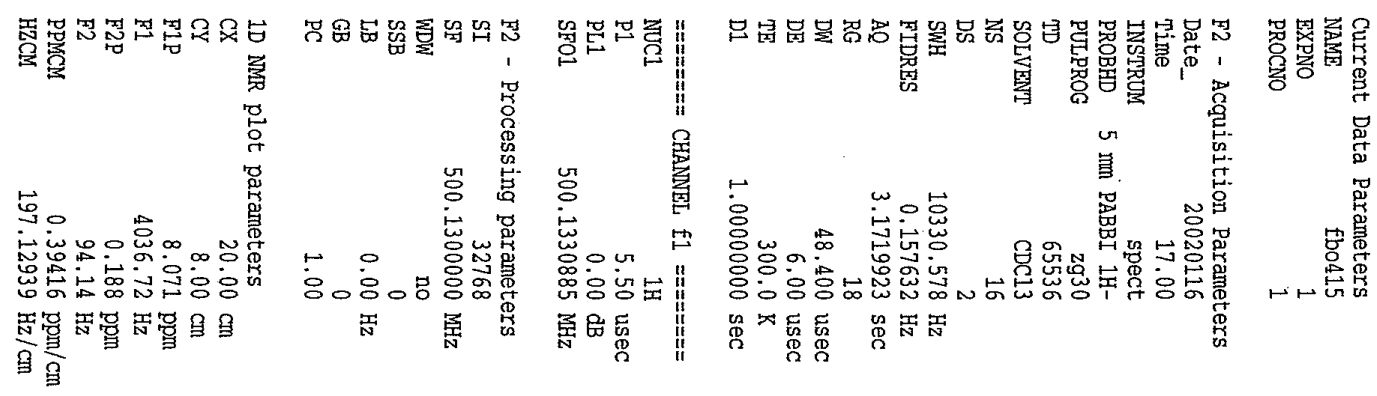




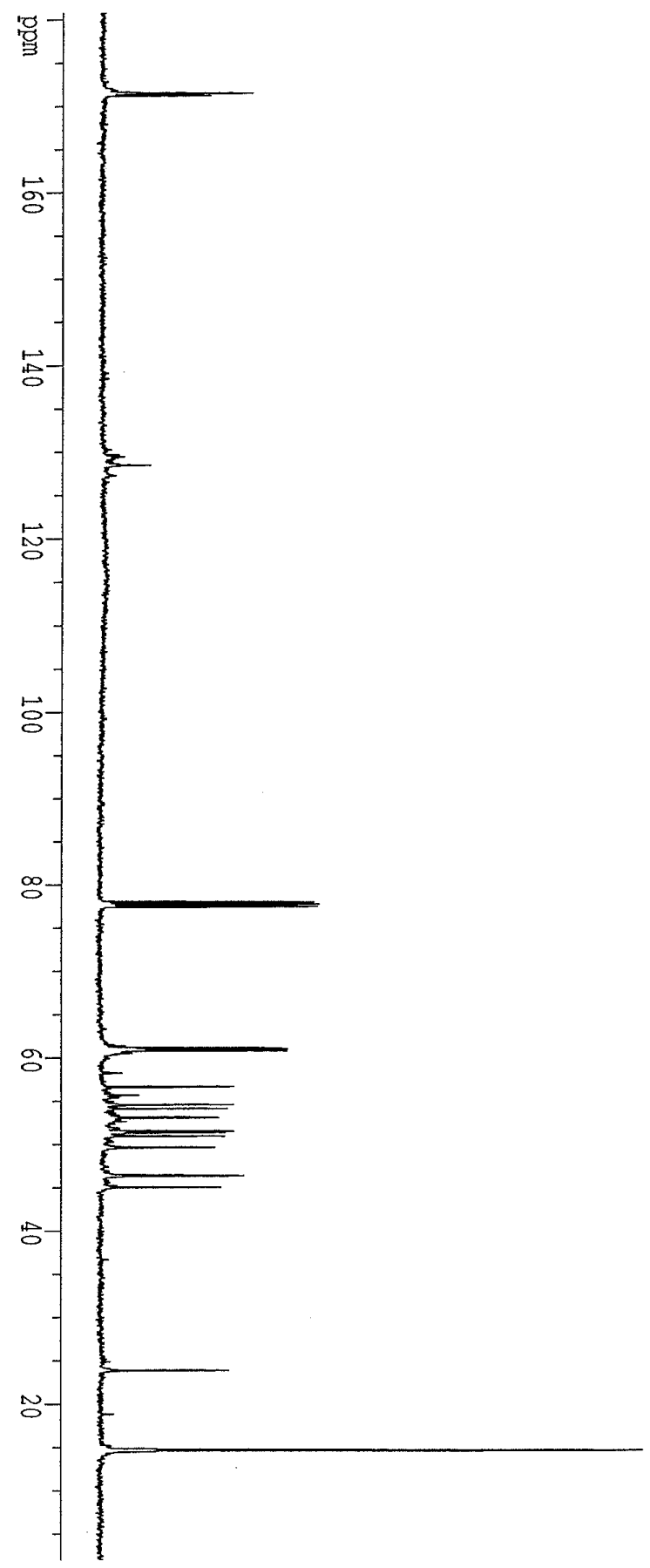

Compound 29

ppm
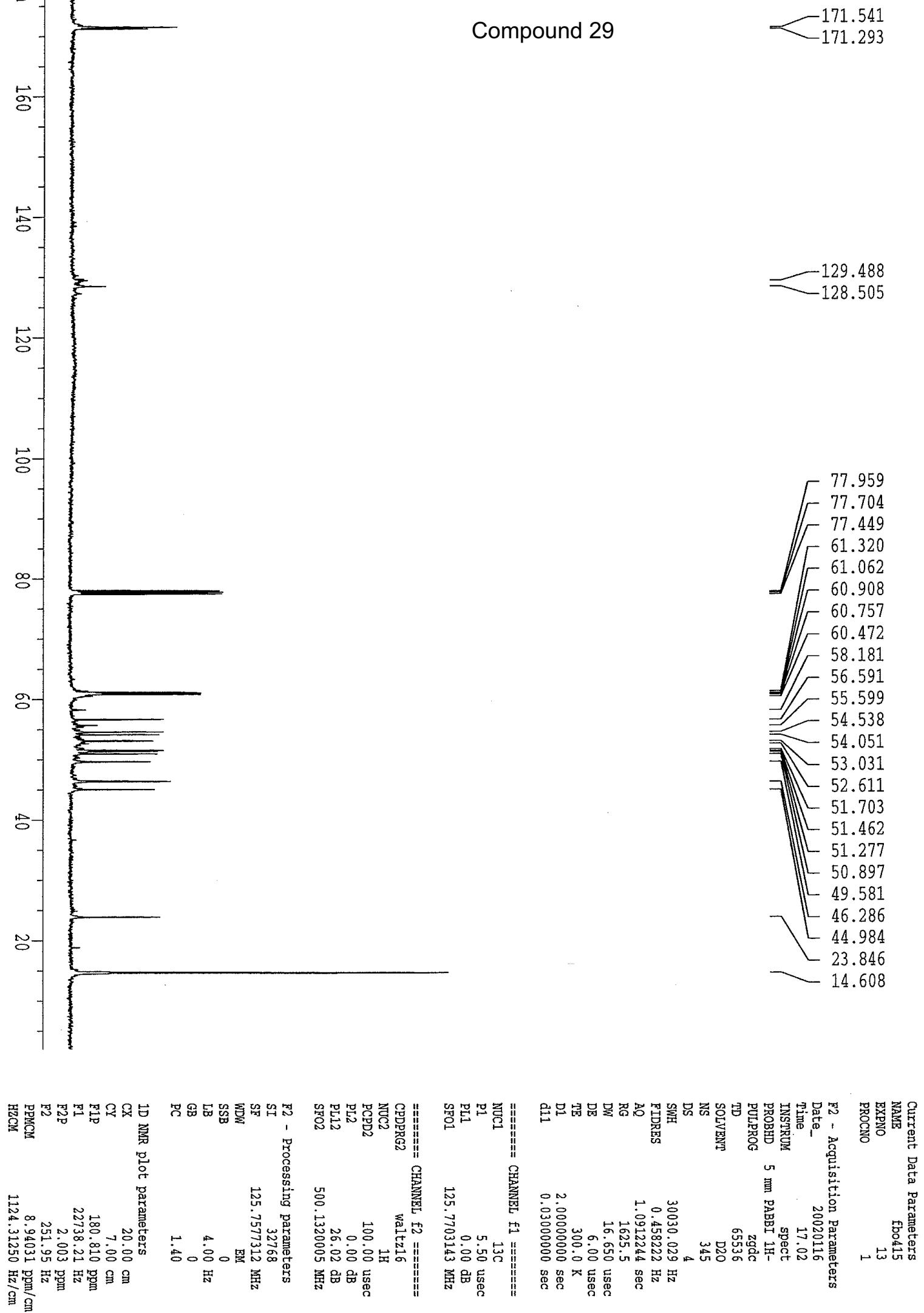

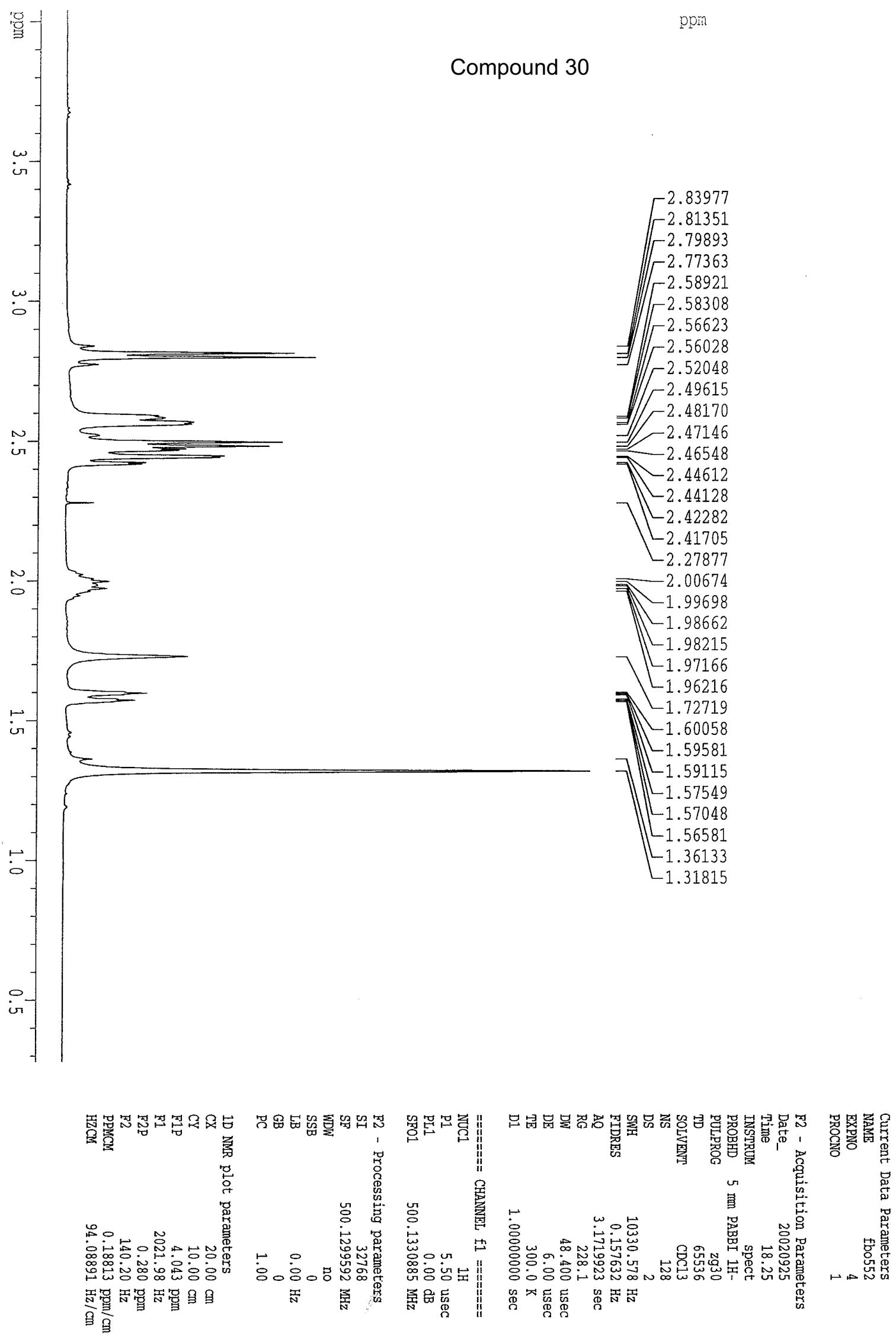


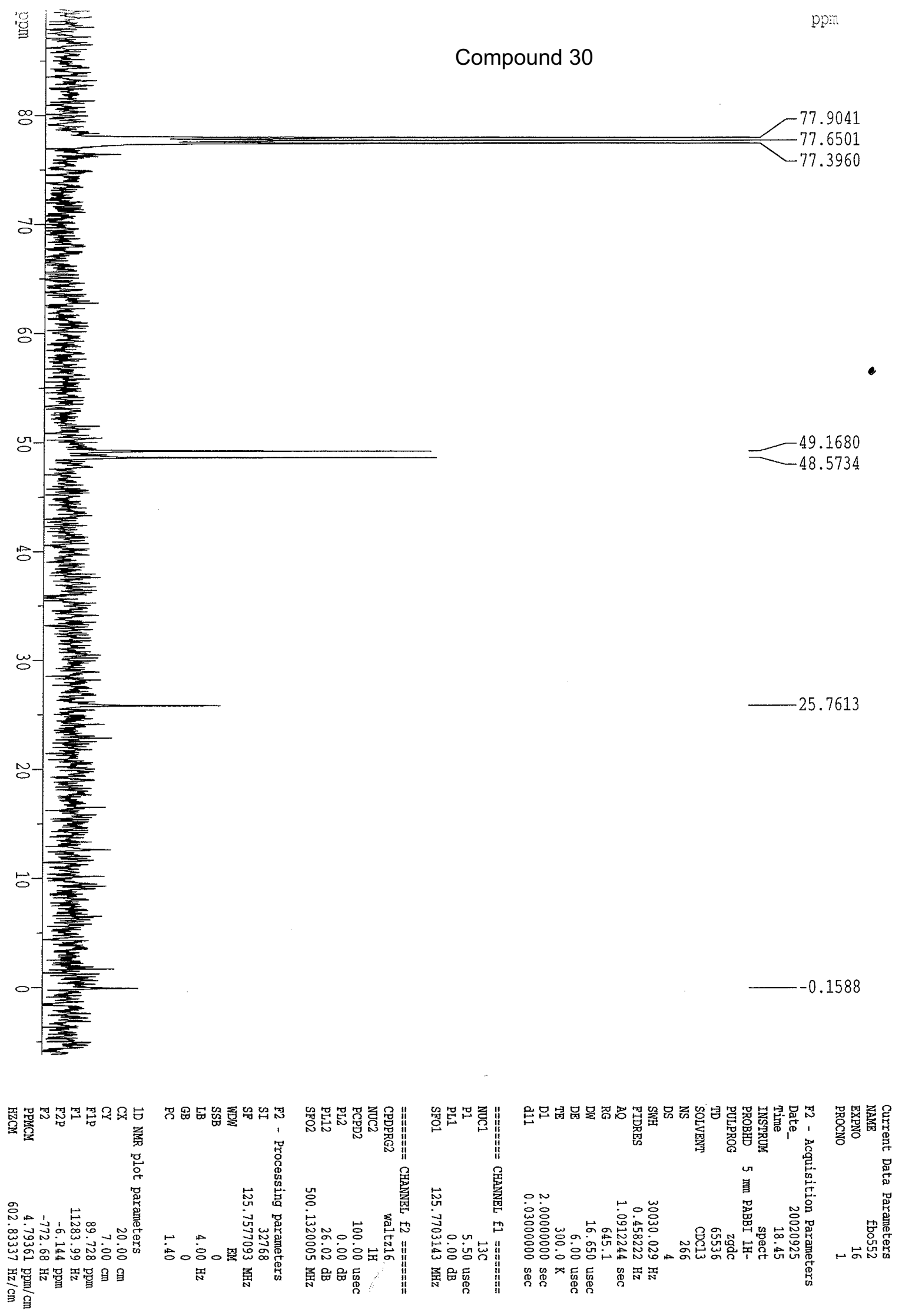




\section{Graphical abstract}

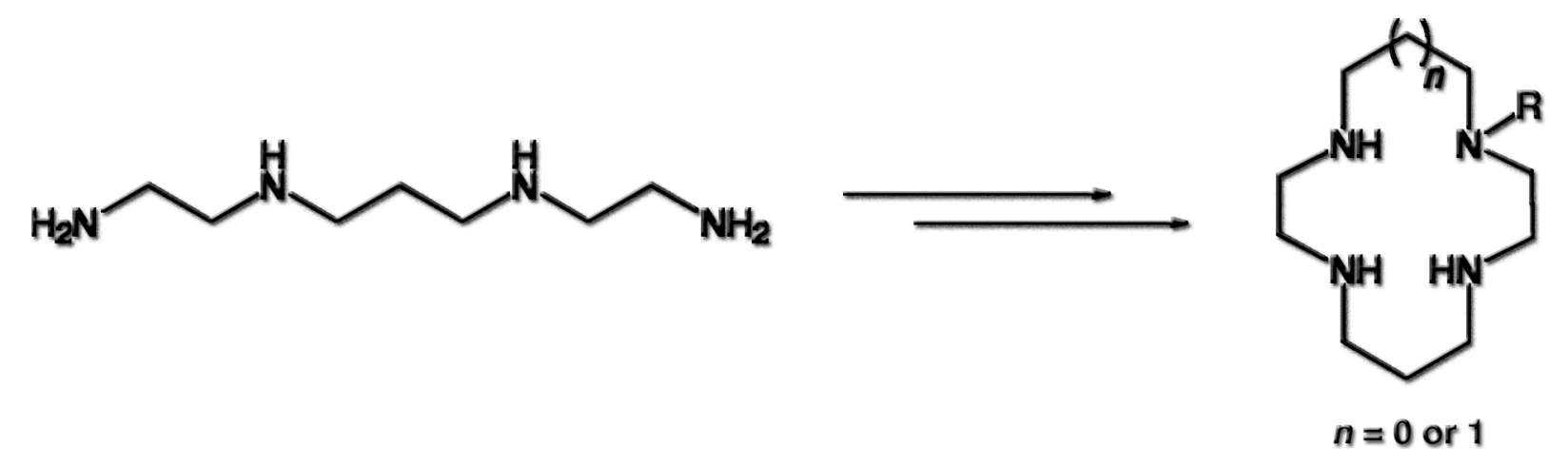

Regioselective N-functionalization of Tetraazacycloalkanes 